OPEN ACCESS

Edited by:

Lars Bejder,

University of Hawai'i at Mānoa,

United States

Reviewed by:

Katherine McHugh,

Chicago Zoological Society,

United States

Valeria Senigaglia,

Murdoch University, Australia

Guido J. Parra

Flinders University, Australia

${ }^{*}$ Correspondence:

Janet Mann

mannj2@georgetown.edu

Specialty section:

This article was submitted to

Marine Megafauna,

a section of the journal

Frontiers in Marine Science

Received: 15 October 2020

Accepted: 18 February 2021

Published: 11 March 2021

Citation:

Mann J, Foroughirad $V$

McEntee MHF, Miketa ML, Evans TC, Karniski C, Krzyszczyk E,

Patterson EM, Strohman JC and

Wallen MM (2021) Elevated Calf Mortality and Long-Term Responses

of Wild Bottlenose Dolphins

to Extreme Climate Events: Impacts

of Foraging Specialization

and Provisioning.

Front. Mar. Sci. 8:617550

doi: 10.3389/fmars.2021.617550

\section{Elevated Calf Mortality and Long-Term Responses of Wild Bottlenose Dolphins to Extreme Climate Events: Impacts of Foraging Specialization and Provisioning}

\author{
Janet Mann ${ }^{*}$, Vivienne Foroughirad ${ }^{1}$, Molly H. F. McEntee ${ }^{1}$, Madison L. Miketa', \\ Taylor C. Evans ${ }^{1}$, Caitlin Karniski' ${ }^{1}$, Ewa Krzyszczyk ${ }^{1}$, Eric M. Patterson ${ }^{1,2}$, \\ John C. Strohman' and Megan M. Wallen'
}

\footnotetext{
'Department of Biology, Georgetown University, Washington, DC, United States, ${ }^{2}$ Office of Protected Resources, National Marine Fisheries Service, National Oceanic and Atmospheric Administration, Silver Spring, MD, United States
}

As demands for wildlife tourism increase, provisioning has become a popular means of providing up-close viewing to the public. At Monkey Mia, Shark Bay, Australia, up to five adult female Indo-Pacific bottlenose dolphins (Tursiops aduncus) visit a $100 \mathrm{~m}$ stretch of beach daily to receive fish handouts. In 2011, a severe marine heatwave (MHW) devastated seagrass and fish populations in Shark Bay. Offspring survival declined precipitously among seagrass specialists (dolphins that forage disproportionately in seagrass habitat). As all provisioned dolphins at the site are seagrass specialists, we examined how provisioned and non-provisioned seagrass specialists responded to the MHW. Using 27 years of data we compare habitat use, home range size, calf mortality, and predation risk between provisioned and non-provisioned females and their offspring before and after the MHW. Our results show that provisioned females have extremely small home ranges compared to non-provisioned females, a pattern attributable to their efforts to remain near the site of fish handouts. However, weaned offspring (juveniles) born to provisioned females who are not provisioned themselves also had much smaller home ranges, suggesting a persistent maternal effect on their behavior. After the MHW, adult females increased their use of seagrass habitats, but not their home range size. Provisioned females had significantly lower calf mortality than non-provisioned females, a pattern most evident pre-MHW, and, in the first 5 years after the MHW (peri-MHW, 2011-2015), calf mortality did not significantly increase for either group. However, the ecosystem did not recover, and post-MHW (2016-2020), calf mortality was substantially higher, regardless of provisioning status. With few survivors, the impact of the MHW on juvenile mortality post-weaning is not known. However, over three decades, juvenile mortality among offspring of provisioned vs. non-provisioned females did not statistically differ. Thus, the survival benefits accrued to calves in the provisioned group likely cease after weaning. Finally, although shark attack rates on seagrass specialists did not change 
over time, elevated predation on calves cannot be ruled out as a cause of death postMHW. We discuss our results as they relate to anthropogenic influences on dolphin behavioral plasticity and responses to extreme climate events.

Keywords: wildlife provisioning, bottlenose dolphins, plasticity, marine heat wave, extreme climate events, specialization

\section{INTRODUCTION}

Anthropogenic impacts on wildlife are exacerbated indirectly by climate change and extreme climate events (Harris et al., 2018), and directly through noise, chemical pollution, habitat destruction and loss, direct harvesting - and by tourism (Shannon et al., 2016; Johnson et al., 2017; Trave et al., 2017). At the same time that human disturbance is becoming more pervasive, interest in close viewing of and contact with wildlife continues to rise. Nature-based tourism and recreation accounts for $11 \%$ of global GDP and 10\% global employment (World Tourism Organisation, 2018), at least before the COVID-19 pandemic which has placed 100-120 million jobs at risk (World Tourism Organisation, 2020).

One way wildlife tourism can virtually guarantee up-close experiences is through provisioning. However, provisioning has well-documented costs to wildlife including increased intraspecific and human-directed aggression, decreased home ranges (Orams, 2002), altered community compositions (Brena et al., 2015), altered behavioral budgets (Samuels and Bejder, 2004; Foroughirad and Mann, 2013), increased risks of injury and entanglement (Christiansen et al., 2016), and increased stress, disease, and health risks (Becker et al., 2015; Murray et al., 2016; Cox and Gaston, 2018; Strandin et al., 2018; Nelson et al., 2019). Benefits to wildlife from provisioning, particularly increased survival and reproduction, have also been documented, but such benefits are less common when provisioning occurs for tourism rather than for conservation (Murray et al., 2016). One cost shared by humans and wildlife is that with elevated contact comes accelerated risk of zoonotic and anthroponotic infectious diseases (Ahmad et al., 2020; Everard et al., 2020). But, human benefits such as enhanced nature experiences and economic benefits are well documented (e.g., Cox and Gaston, 2018). Wildlife tourism, strengthened by provisioning, can also protect areas by reducing pressure on local communities to engage in development, resource extraction or other types of exploitation in favor of supporting the tourism industry (Yamagiwa, 2010; Maréchal et al., 2016).

While nature-based tourism spans all ecosystems, coastal marine areas are arguably among the most threatened by such activities (Lusseau and Mancini, 2018). Furthermore, marine wildlife tourism has additional challenges given the unpredictability of wildlife encounters at sea, especially when targeting highly desirable charismatic megafauna (marine mammals, turtles, rays, and sharks), objectives which incentivize provisioning when possible (Brena et al., 2015). In addition to dolphins, sea turtles (Smulders et al., 2021), sharks and rays (Brena et al., 2015) are commonly provisioned to promote interactions with tourists. Wild dolphins are provisioned at four sites in Australia through special permit (Environment Protection and Biodiversity Conservation Act, 1999), most famously, at Monkey Mia, Shark Bay in Western Australia, where up to five female adult Indo-Pacific bottlenose dolphins (Tursiops aduncus) visit a $100 \mathrm{~m}$ stretch of beach daily to receive fish handouts. Here we explicitly examine the interaction between direct anthropogenic activities (i.e., provisioning) and indirect anthropogenic effects (i.e., climate change and extreme heat events) on wild bottlenose dolphins at Monkey Mia, Shark Bay.

Specifically, we argue that although provisioning, when carefully managed, can benefit humans and dolphins alike, it also has marked impacts on dolphin activity, ranging behavior and habitat use, with long-lasting maternal effects, thereby constraining the provisioned dolphin's ability to respond to dramatic ecological changes caused by extreme climate events. This is particularly evident when their primary foraging habitat is severely damaged.

In the early years $(<1994)$ of provisioning at Monkey Mia, deleterious impacts in terms of female calving success were well documented (Mann et al., 2000; Mann and Kemps, 2003). Following management changes in feeding protocols, calving success increased, although behavioral differences between provisioned females and their offspring and non-provisioned counterparts persisted (Foroughirad and Mann, 2013). Most prominently, calves born to provisioned females rested less, had less nursing access, and foraged and separated more from their mothers than calves of non-provisioned females. However, provisioned adult females had similar behavioral activity budgets to non-provisioned females when they were away from the human interaction area. At another provisioning site, in Bunbury, Western Australia, female calving success was also negatively impacted by provisioning (Senigaglia et al., 2019), presumably from harmful interactions with humans (such as boat begging), rarely engaged in by non-provisioned dolphins (Mann et al., 2018). At the third bottlenose dolphin site, in Tangalooma, Australia, calf survival was reported to be $100 \%$ with few deleterious impacts of provisioning (Neil and Holmes, 2008) other than aggressive behavior toward humans (Orams et al., 1996). Yet, some mortality in Tangalooma has occurred since the 2008 paper was published, and the non-provisioned dolphins have not been closely monitored for comparison. Finally, at Tin Can Bay in Queensland, where a different species, the Australian humpback dolphin (Sousa sahulensis) is provisioned, few empirical studies on the effects of provisioning are published (Barber, 2016). As demonstrated by studies at Monkey Mia, long-term data can inform best practices for provisioning; the successes of Monkey Mia resulted in changed protocols at Tangalooma and Bunbury. Our current study utilizes this longterm data to examine whether provisioned animals and their 
offspring are more resilient or vulnerable to environmental perturbations caused by climate change.

Extreme climate events, such as marine heat waves (MHWs), have increased in recent years as predicted by global climate change models (Oliver et al., 2018). In 2011, a catastrophic MHW with sustained temperatures $2-5^{\circ} \mathrm{C}$ above average devastated seagrass communities in Shark Bay, Australia, constituting the single largest acute loss of seagrass biomass in recorded history (Strydom et al., 2020). With profound loss of foundational species, other fauna suffered, including fish, invertebrates, green turtles, sea snakes, dugongs and bottlenose dolphins (Wernberg et al., 2013; Miketa, 2018; Caputi et al., 2019; Nowicki et al., 2019; Wild et al., 2019). Apex predators in particular might be both diagnostic and biotic multipliers of the impacts of extreme climate events due to the extent of their interactions and effects on other species (Nowicki et al., 2019). However, tiger shark abundance was not affected by the MHW, even though their primary prey, sea snakes, green turtles and dugongs, were severely impacted (Nowicki et al., 2019). As tiger sharks are the only predator known to threaten bottlenose dolphins in Shark Bay (Heithaus, 2001a,b), we hypothesized that the reduction in preferred prey of tiger sharks could result in an increase in the attack rate on bottlenose dolphins, as evidenced by fresh wounds and scars.

Although entire populations may be impacted by catastrophic events and climate change, individuals can also be affected differently depending on their ecological niche, behavioral phenotype, and plasticity. But, the longitudinal data that are necessary for studying such intraspecific responses are scarce (Canale and Henry, 2010; Jenouvrier, 2013; Boutin and Lane, 2014; Lescroël et al., 2014; Merrick and Koprowski, 2017). Bottlenose dolphins, which we have studied in Shark Bay since 1984, show diverse foraging tactics that are socially inherited, primarily from the mother to offspring (Mann and Sargeant, 2003; Sargeant et al., 2007; Mann et al., 2008; Sargeant and Mann, 2009). Given such heterogeneous phenotypes, longitudinal data on Shark Bay dolphins can demonstrate how individuals are differentially affected by extreme climate events. To date, evidence suggests that dolphins specializing in seagrass habitats were more heavily impacted by the MHW. Research (Miketa, 2018) in the eastern gulf of Shark Bay compared responses of dolphins to the MHW among dolphins classified by 3 foraging types: (1) seagrass specialists (those that use seagrasses for foraging more than expected based on seagrass availability); (2) dolphins that specialize in foraging with sponge-tools and are restricted to deeper channel habitats with little seagrass (Mann et al., 2008); and (3) those that do not specialize in seagrass habitats nor sponge tool-use. Initially, following the MHW, most dolphins spent more time in seagrass habitat and appeared to have higher foraging success, possibly taking advantage of less-dense seagrass where locating and capturing fish might be easier (Miketa, 2018). In the western gulf of Shark Bay (Wild et al., 2019), dolphins that used shallower habitats $(<10 \mathrm{~m})$ had elevated mortality, although this study did not focus on seagrass specialists per se. Wild et al. (2019) suggested that sponge-tool-users, which use deeper waters, averaging $>10 \mathrm{~m}$, might have been protected from the negative impacts from the MHW because they rarely use seagrass habitat.

Despite extensive literature on the impacts of provisioning on wildlife, little or no research is available on how provisioned animals respond to extreme environmental change. Delphinids in particular, which have slow life histories, are known for their diverse behavior and plasticity (Patterson and Mann, 2015); longitudinal research is particularly critical for understanding impacts in such systems. Our 37-year study of Shark Bay bottlenose dolphins (Tursiops aduncus, hereafter "dolphins") provides an ideal means to investigate how behaviorally plastic animals, provisioned by humans, respond to extreme environmental perturbations.

\section{Goals of the Current Study}

Given that all of the dolphins provisioned at Monkey Mia are seagrass specialists, we investigated whether provisioning provided a protective buffer to these dolphins from the environmental impacts of the MHW or if it constrained their ability to respond to the cascading environmental impacts caused by the MHW. To do this, we compare home range size, degree of foraging specialization, and offspring survival and spatial ecology of provisioned and non-provisioned dolphins to examine how they responded to the catastrophic MHW events and the resulting habitat devastation. We focused heavily on home range and habitat use as these are critical elements of a species' ecology, and determinative of resources that individuals have access to. We restricted our comparisons to provisioned dolphins and nonprovisioned dolphins that have the same foraging specialization (foraging in shallow seagrass habitat) and overlapping home ranges. We also examined the long-term impacts of provisioning on the foraging and spatial ecology of their offspring because our previous work demonstrates strong vertical transmission of foraging behavior and ecology (Mann et al., 2008; Sargeant and Mann, 2009), which has implications for individual plasticity in response to environmental change.

Here we are explicitly interested in provisioned and nonprovisioned seagrass specialists, and how the MHW differentially impacted them. We ask the following questions: (1) What impact does provisioning have on dolphins' spatial ecology, including that of their non-provisioned offspring? (2) How were seagrassspecialist dolphins impacted by the MHW and were provisioned dolphins, a subgroup of seagrass specialists, differently affected? (3) What was the nature of these impacts on provisioned and non-provisioned dolphins in terms of survival, reproduction, and spatial ecology? (4) Were the impacts cumulative during the 10 years post-MHW or was there evidence of recovery? (5) What other ecological factors likely contributed to these impacts (e.g., prey and predation)?

\section{MATERIALS AND METHODS}

\section{Study Site}

Since 1984, The Shark Bay Dolphin Research Project has collected behavioral, demographic, genetic, and ecological data on over 1,700 wild Indo-Pacific bottlenose dolphins (T. aduncus) in 
Shark Bay, Western Australia $\left(25^{\circ} 47^{\prime} \mathrm{S}, 113^{\circ} 43^{\prime} \mathrm{E}\right)$. Shark Bay is a UNESCO World Heritage Site with extensive seagrass beds and a stable dolphin population (Manlik et al., 2016), characterized by bisexual philopatry (Tsai and Mann, 2013). Our study site is located within the Faure Sill region of Shark Bay, which experienced a $20 \%$ total reduction in seagrass cover from 2010 to 2014 , with even higher losses in localized regions based on the fine-scale duration and extent of heat stress experienced (Strydom et al., 2020). The area has shown little recovery to date (Strydom et al., 2020).

\section{Surveys}

Surveys are opportunistic boat-based observations of dolphins in which group membership, predominant activity, and ecological data (habitat type, sea surface temperature, and water depth) are recorded via scan sampling (Karniski et al., 2015). Individual dolphins are identified by dorsal fin shape, nicks, and other markings (Photo ID, Würsig and Jefferson, 1990; Bichell et al., 2018). Ages are determined by known birth date (Mann et al., 2000), degree of ventral speckling (Krzyszczyk and Mann, 2012), or body size. Dolphin sex is determined by sightings of the genitals, persistent close association with a dependent calf, and/or genetically (Mann et al., 2000; Krützen et al., 2002). Age, sex, and maternal kinship are known for all dolphins in the current study. Surveys are the primary means of determining home range, habitat use, life history traits, and predation risk, but other observational data from focal follows (Karniski et al., 2015) also contribute.

\section{Description of Provisioning Site}

Monkey Mia is the longest-running provisioning site for wild bottlenose dolphins in the world. Dating as far back as the 1960s, at least 14 adult dolphins have regularly visited the shores of Monkey Mia, Shark Bay, to accept fish hand-outs and touching from fishers and tourists standing in knee-deep water (Mann et al., 2000; Mann and Kemps, 2003; Foroughirad and Mann, 2013). Several adult males were fed until their deaths in 1989, after which the Department of Parks and Wildlife (Division of the Department of Biodiversity and Attractions, DBCA) changed this policy to prohibit male feeding because of elevated aggression toward humans and other dolphins. Since 1994, dolphins are limited to $2 \mathrm{~kg}$ of fish per day (typically less to keep the amount to $<10 \%$ of their predicted daily intake), touching is prohibited, and no more than five adult females from the same three matrilines are part of the program at any given time.

The current provisioning practices at Monkey Mia are strict and involve detailed protocols. The area where provisioning takes place (the dolphin experience area) is approximately $100 \mathrm{~m} \times 40 \mathrm{~m}$ with a jetty adjacent to the provisioning site. Each morning, when the provisioned dolphins typically come into the experience area, DBCA rangers give a $\sim 20$ min presentation before the feeding. Each provisioned female lines up at a different bucket, managed by DBCA volunteers (Figure 1). Most feeding sessions provide 2-3 fish per female and finish in less than $5 \mathrm{~min}$. Feedings are restricted to three per day and cannot occur after noon (Mann et al., 2018). Non-provisioned dolphins, including nursing and weaned offspring of the provisioned dolphins also visit the area, but are not fed and typically socialize, rest, or forage nearby. During the course of this study (1994-2020), three adult females, all born to provisioned females, were newly recruited to the provisioning program. Two were introduced to the program and began taking fish regularly when they had their first offspring (both pre-MHW). One female, the 18-year-old daughter of a provisioned female, was recruited to the provisioning program in 2016 after she had three offspring (two died pre-weaning, one survived). She is the only female who was not provisioned for a substantial portion of her adult years. She is included in the nonprovisioned adult sample prior to 2016 and in the provisioned sample after 2016. No juvenile dolphins (4-10 years of age) were provisioned during the course of the study.

\section{Adult Females for Analysis}

Because all six provisioned adult females in our sample are seagrass specialists (defined as those that use seagrass greater than expected based on the availability of seagrass habitat) and seagrass specialists were presumably most impacted by the MHW, our non-provisioned comparison group includes adult females that met three criteria: (1) they were observed on at least 35 days before the MHW; (2) they overlapped in home range with the provisioned group by $50 \%$ or more; and (3) they were also seagrass specialists before the MHW (see home range section for details). Out of 165 potential females who met our sighting requirement, 21 non-provisioned adult (>11 year-old) female seagrass specialists met all three criteria.

\section{Marine Heat Wave Time Periods}

Our analyses were divided into three time periods: before the heat wave, pre-MHW (1994-2010); the first 5 years after the heat wave, peri-MHW (2011-2015); and 6-10 years after the heat wave, post-MHW (2016-2020). These time periods were delineated based on the change in feeding protocols at Monkey Mia in 1994 (Foroughirad and Mann, 2013) and the expectation that the impact of the MHW might not be immediate given this species slow life history (e.g., the average weaning age is 4 years; Mann et al., 2000; Karniski et al., 2018). Previous work did not find higher calf mortality in the immediate aftermath of the MHW, but reported a lower calving rate (Wild et al., 2019) which can reflect a combination of reproductive or demographic changes including calf mortality, prenatal loss, conception rate, or weaning age. Calves who were under 1 year of age when the MHW hit were considered to be in the peri-MHW group.

\section{Home Range}

Home ranges were constructed for all females that had a minimum of 35 sightings before the MHW (Supplementary Figure 1) using the R package adehabitatHR (Calenge, 2006). Location data were filtered to include only the last point per day per individual to increase independence between points and reduce biases associated with sighting individuals near our boat launching location (near the dolphin interaction area). Home ranges were measured using kernel utilization distributions (UDs) across $250 \mathrm{~m} \times 250 \mathrm{~m}$ grid cells. The smoothing parameters were set to the default ad hoc reference bandwidth values (Worton, 1989, 1995) calculated independently 

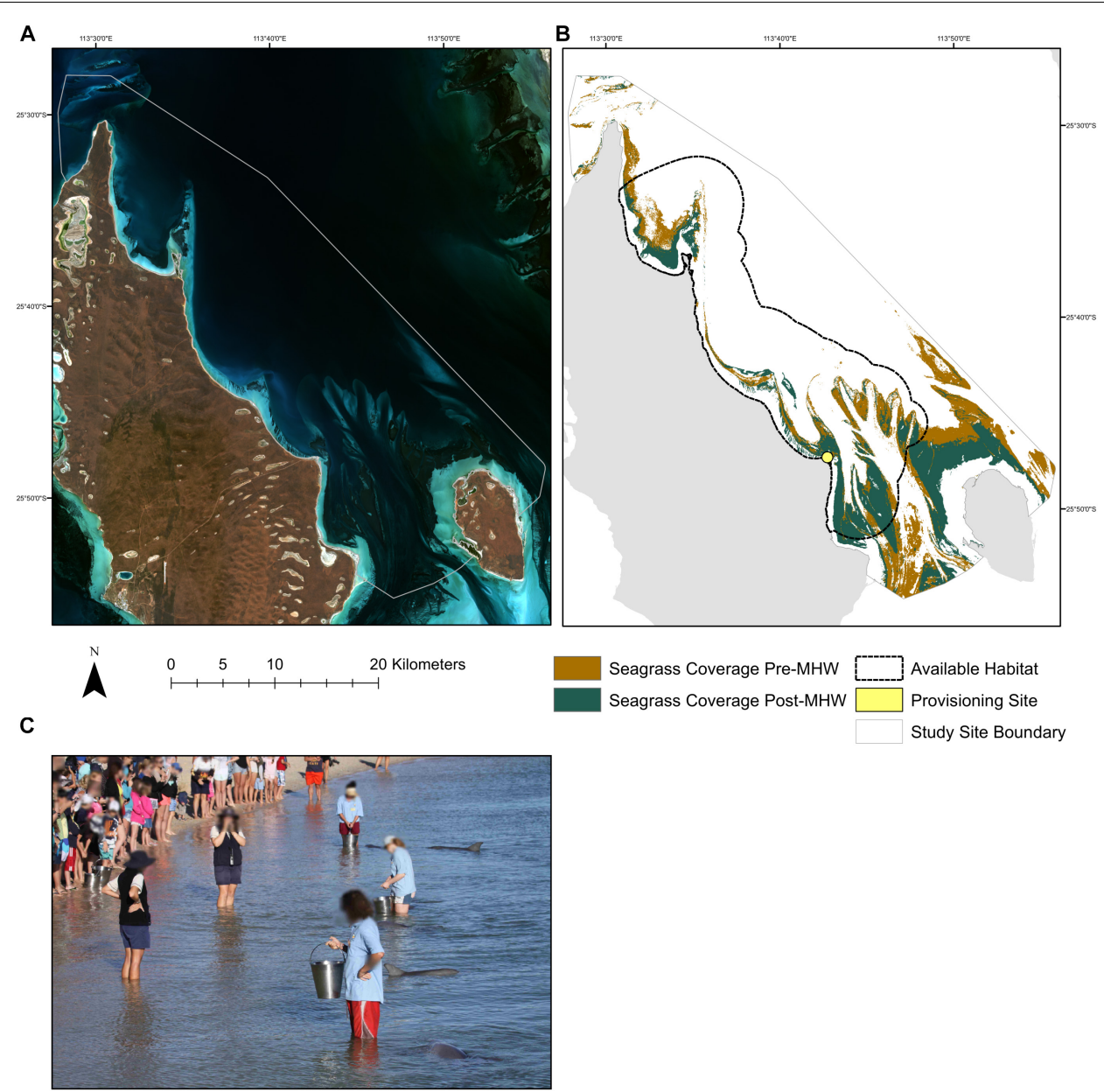

FIGURE 1 | The location of the study site and provisioning scene. (A) Landsat-8 imagery of the study site from June 2015 courtesy of United States Geological Survey. (B) Map of the study area showing the extent of seagrass beds before and after the MHW. The boundaries of the study area represent the intersection of the minimum convex hulls around all survey effort during each time period (pre-MHW, 1994-2010; peri-MHW, 2011-2015; post-MHW, 2016-2019). The dotted black line represents the area of available habitat for dolphins in our study. The provisioning site is shown by the yellow circle located at S $25^{\circ} 47^{\prime} 52.4^{\prime \prime}, \mathrm{E} 113^{\circ} 43^{\prime} 12.9^{\prime \prime}$. (C) Image from a feed in 2015, Photo Credit: Ewa Krzyszczyk.

for each individual $\left[\mathrm{h}_{\text {ref }}\right.$ median (interquartile range) $=1,018 \mathrm{~m}$ (435-1,311 m)]. A simplified boundary derived from a portion of the coastline was included as a barrier (Benhamou and Cornélis, 2010). Any remaining land area was removed from all final UDs and the probability densities of each UD were restandardized to 1 . We then used 95\% kernel density estimates to calculate Bhattacharyya's affinity index between each nonprovisioned female and each of the six provisioned females to measure home range similarity (Fieberg and Kochanny, 2005). We then selected only those non-provisioned females that had an average overlap coefficient with the provisioned females of 0.5 or greater as our comparison group. This ensured that the comparison group experienced the same habitats damaged by the MHW as the provisioned dolphins. Seagrass habitats experienced varying degrees of damage depending on the location (Strydom et al., 2020).

To compare home range sizes before, during, and after the $\mathrm{MHW}$, we recalculated home range size for these individuals with a minimum of 35 sightings as adults per time period, so not all females were included in every time period. For the pre-MHW period, we only used data from the 5 years immediately prior to the heatwave (2005-2010) so that the size of the total ranging area would not be biased upward by the longer time period. Because home range size measurements are sensitive to sample size (Noonan et al., 2019), for individuals with greater than 35 sightings, we estimated home range size by averaging the size of home ranges created from randomly sampling 35 sightings, 100 times, per dolphin. Land was removed from all final home range estimates. We also removed sightings of females when they were in consortships with adult males. During these events, males tend to escort females away from their core home range (Wallen et al., 2016). We compared home range sizes between females using a linear model in $\mathrm{R}$ ( $\mathrm{R}$ Core Team, 2020) including time frame (pre, peri, and post), provisioning status, and their interaction as predictors. 
Until 2018, we did not conduct surveys within 800-1,000 m of the dolphin experience area and bordering waters as we would end up sampling the provisioned dolphins nearly every morning when they are near the experience area. As such, given that they spent much of their day in and around that area, our habitat analyses likely overestimate the amount of time the dolphins spend away from the provisioning area prior to 2018 .

To examine the long-term impacts of provisioning on offspring spatial ecology, we compared the home range sizes of juvenile offspring of the provisioned and non-provisioned females using the 35 sightings threshold per individual. We compared range size between all juvenile offspring using a linear model including sex, provisioning status of the mother, whether the juvenile was weaned before or after the MHW, and whether the juvenile survived to age 10 .

While we did not have enough data to simultaneously investigate the interacting effects of age, time period, and provisioning status on home range sizes throughout the lifespan, we conducted an additional analysis in which we expanded our study subjects to include all females in our study site who had at least 35 sightings both in their juvenile period and in the adult period $(n=25)$ to look at the individually-specific patterns of home range size change with age. Change in home range size was compared between juvenile and adult non-provisioned females using a two-sided paired permutation test implemented in the $\mathrm{R}$ package coin (Hothorn et al., 2008).

\section{Selection Ratios for Habitat Use}

The core area of the Shark Bay study site is comprised of embayment plains $(5-13 \mathrm{~m})$, shallow sand flats $(0.5-4 \mathrm{~m})$, seagrass beds $(0.5-4 \mathrm{~m})$, and bisecting deep channels $(7-13 \mathrm{~m})$. Substrate cover for the shallow water habitats is typically visually assigned during boat-based surveys, and supplemented with remote sensing data when visual data is absent due to turbidity, cloud cover, etc. Total seagrass availability in the study area was determined using supervised classification of satellite imagery and bathymetry trained on validation points collected during boat-based surveys (see Supplementary Material for details). For this study, individual sightings within the study bounds were assigned to either seagrass habitat or other based on intersecting sighting coordinates with habitat spatial layers, and these data were then compared to total seagrass availability within the study site by calculating resource selection ratios using Manly's type II design (Manly et al., 2002). Habitat use was defined using only sightings in which the female was observed foraging. Available habitat can be difficult to delineate, especially for highly mobile animals such as bottlenose dolphins, since the area over which they regularly range also represents a form of habitat selection (O'Brien et al., 2020). Since we were primarily interested in the area accessible to the provisioned dolphins and those with similar space use, we first delineated a subsection of our study site as available by drawing a boundary around all the home ranges of animals that met our overlap threshold with the provisioned females, and then adding a small $1 \mathrm{~km}$ buffer (Figure 1). As with the ranging data, selection ratios calculated over the period of 1994-2010 were used to designate candidate animals for the comparison group, and then data were subset to only sightings of those animals as adults from 2005 to 2010 to make all time periods comparable in length for comparison. Seagrass selection ratios were calculated for each of the provisioned females and their comparison group in each time period, and then compared between these groups using a linear model including time frame (pre, peri, and post), provisioning status, and their interaction.

\section{Survival Analyses}

We examined calf and juvenile survival using Cox proportional hazards mixed effects models in the package coxme (Therneau, 2015), and plotted Kaplan-Meier survival curves in the survival (Therneau and Lumley, 2015) and survminer (Kassambara et al., 2017) packages in R. Cox PH models are commonly used to model the effects of multiple covariates on time to event (i.e., time to death) data with right-censored observations. Cox $\mathrm{PH}$ mixed effects models allow for the incorporation of random factors, or "frailty terms", to control for differences in baseline mortality hazard between groups (Austin, 2017); here, we used a random factor to control for differences in baseline hazard due to maternal ID. We tested the proportional hazards assumption for each model in the survival package and found no violations. Offspring of provisioned females and non-provisioned seagrass specialists born from 1994 to 2019 were included. We excluded births before 1994 because feeding protocols changed in 1994, resulting in much higher calf survival; before 1994, significantly higher calf mortality among provisioned dolphins compared to non-provisioned is well documented (Mann et al., 2000; Foroughirad and Mann, 2013).

Individuals were right-censored at the age of interest (age 3 for calf analyses, age 10 for juvenile analyses), or at their age on January 01, 2020. Survival was analyzed for 79 offspring (26 born to six provisioned females and 53 born to 18 nonprovisioned females). The offspring of females whose mothers were provisioned, but are/were not provisioned themselves when the offspring were born and dependent (nursing), were included in the non-provisioned sample. One female, who was provisioned as an adult in 2016, has calves in both the non-provisioned and provisioned sample. None of the calves in our sample were provisioned in their juvenile period.

For the calf survival analysis, calves born from January 01, 1994 to July 01, 2010 were considered pre-MHW $(N=16$ provisioned; $N=32$ non-provisioned), calves born from July 02,2010 to July 01,2015 were considered peri-MHW $(N=5$ provisioned; $N=10$ non-provisioned) and calves born after July 01,2015 were considered post-MHW $(N=5$ provisioned, $N=11$ non-provisioned).

We constructed a Cox PH model of survival to age three with MHW category (pre, peri, and post), and mother's provisioning status as fixed factors. To evaluate if provisioned and nonprovisioned females were differentially affected by the MHW, we included an interaction term between MHW category and provisioning status. Maternal ID was included as a random factor.

Survival to age 10 was analyzed for the same 79 offspring born to seagrass specialists. Due to high calf mortality, sample sizes were too limited to analyze juvenile survival across all three MHW categories. Consequently calves born to provisioned mothers $(N=26)$ and to non-provisioned mothers $(N=53)$ from 
1994 to 2019 were pooled across time periods for analysis. We constructed a Cox proportional hazards mixed effect model with provisioning status of mother as a fixed factor and maternal ID as a random factor.

\section{Birth Rate}

We examined calving rate as the number of calves born per year to females of reproductive age who were sighted in that year. This allowed us to directly compare our results with previous work by Wild et al. (2019), which found a decline in calving rate in the western gulf of Shark Bay after the MHW (2011-2017). Calving rate is affected by weaning age and prenatal/calf mortality, in addition to physical condition, and therefore is not necessarily a good proxy for reproductive success [i.e., when calf mortality is high, the calving rate increases because females become pregnant more quickly than if the calf survives to weaning (Mann et al., 2000)]. We included all females who met our home range overlap and seagrass selection ratio cutoffs and who were over the age of 11, regardless of if they had reproduced yet. This resulted in a sample of six provisioned females and 21 non-provisioned females, with one female who was provisioned in 2016 included in both groups. Females entered the sample at the age of 11 or at their age of first birth, whichever occurred first. We calculated the number of calves born to all provisioned and all non-provisioned females in the sample each year in the pre (July 01, 1994 - July 01, 2010), peri (July 02, 2010 - July 01, 2015), and post (July 02, 2015 - July 01, 2020) MHW time periods. All of the females in this sample have high sighting rates (see "Home Range" section above). While it is possible that we missed some stillbirths or calves who died extremely young, we do not expect that to significantly impact our results. We used a Poisson generalized linear model to model the number of calves born each year with MHW time period and provisioning status of the mother as fixed effects. We included an interaction term between provisioning status and time period, and the log of the number of females from our sample who were seen in the year as an offset term to control for the number of available reproductive females. We calculated variance inflation factors in the car package (Fox et al., 2012); all VIF values were below 4 , indicating there are no substantial issues of collinearity. We visually evaluated the model residuals and formally tested for overdispersion in the AER package (Kleiber et al., 2020); we found no evidence of overdispersion $(p=0.9)$.

\section{Shark Bite Rate}

The primary threat to Shark Bay dolphins is the tiger shark (Galeocerdo cuvier), based on lethal attacks (Mann and Barnett, 1999), scarring patterns and prevalence on dolphins (Heithaus, 2001a), and that $94 \%$ of large sharks caught during shark fishing research were tiger sharks (Heithaus, 2001b). Though we cannot accurately measure lethal predation events due to insufficient carcass recovery, prior work in Shark Bay suggests that non-lethal attacks are common; over $74 \%$ of non-calf individuals bear scars from non-fatal shark attacks (Heithaus, 2001a). We therefore used scarring rates as a proxy for shark predation pressure, which we hypothesized may have increased following the reduction in other shark prey species (Nowicki et al., 2019). To investigate whether shark attack risk had changed following the heatwave, we estimated the annual probability of non-lethal shark attacks by documenting fresh shark bites from the appearance of new scars or open wounds.

Using photographs and written records from 2002 to 2019, we calculated the rate of non-lethal shark attack per dolphin per year as a proxy for predation risk. We left-censored the available records to 2002 to match the beginning of consistent usage of digital photography. We compared the probability of observing a fresh shark attack wound each year for each of the six provisioned dolphins and their offspring up until age 10, as well as for the non-provisioned seagrass specialists and their offspring. We compared these probabilities relative to the MHW using two binomial generalized linear models, one for adults, and one for offspring which included offspring age as a covariate in addition to time period and provisioning status. This included 6 provisioned and 18 non-provisioned adult females, with 18 and 21 of their offspring, respectively.

All analyses were conducted in $\mathrm{R}$ version 4.0.3 (R Core Team, 2020).

\section{RESULTS}

\section{Home Range Size}

Provisioned dolphins had far smaller home ranges $\left(19.7 \pm 7.2 \mathrm{~km}^{2}\right)$ than non-provisioned dolphins $\left(62.3 \pm 29.2 \mathrm{~km}^{2}\right)$ across all time frames (Figure 2 and Table $\left.\mathbf{1}\right)$. Juvenile offspring of provisioned dolphins also had much smaller home ranges than the offspring of non-provisioned counterparts even though they range independently post-weaning (Figure 3 and Table 2). A paired comparison of non-provisioned female home range size between the juvenile and adult life stage showed that individual home range sizes persist into adulthood $(z=1.367, p$-value $=0.172, n=25)$ (Figure 4). Another indication that provisioning has pervasive impacts on home range size is illustrated by the one adult female, Kiya, who was provisioned at age 18. Her tiny home range from the ages of 10-17 shrunk to an even smaller size post-provisioning (Figure 5). This is particularly evident by comparing her to her paternal half-sister, born the same year, who is also a seagrass specialist, but whose matriline was never provisioned and who has maintained a consistent home range approximately 3 times the size of Kiya's (Figure 5).

\section{Habitat Use}

By definition, all seagrass specialists, including the provisioned dolphins, had seagrass selection ratios $>1.0$ before the MHW (1994-2010), and the degree of seagrass specialization actually increased over the 3 time periods. Seagrass specialists used seagrass more both during the peri- and post-MHW periods than before the MHW (Figure 2 and Table 1). Increased seagrass selection ratios can be both a function of individuals spending more time in seagrass, and the total area of seagrass available being substantially lower following the heatwave. Interestingly, no female in our sample reduced their seagrass use below the level required for specialization following the heatwave. 

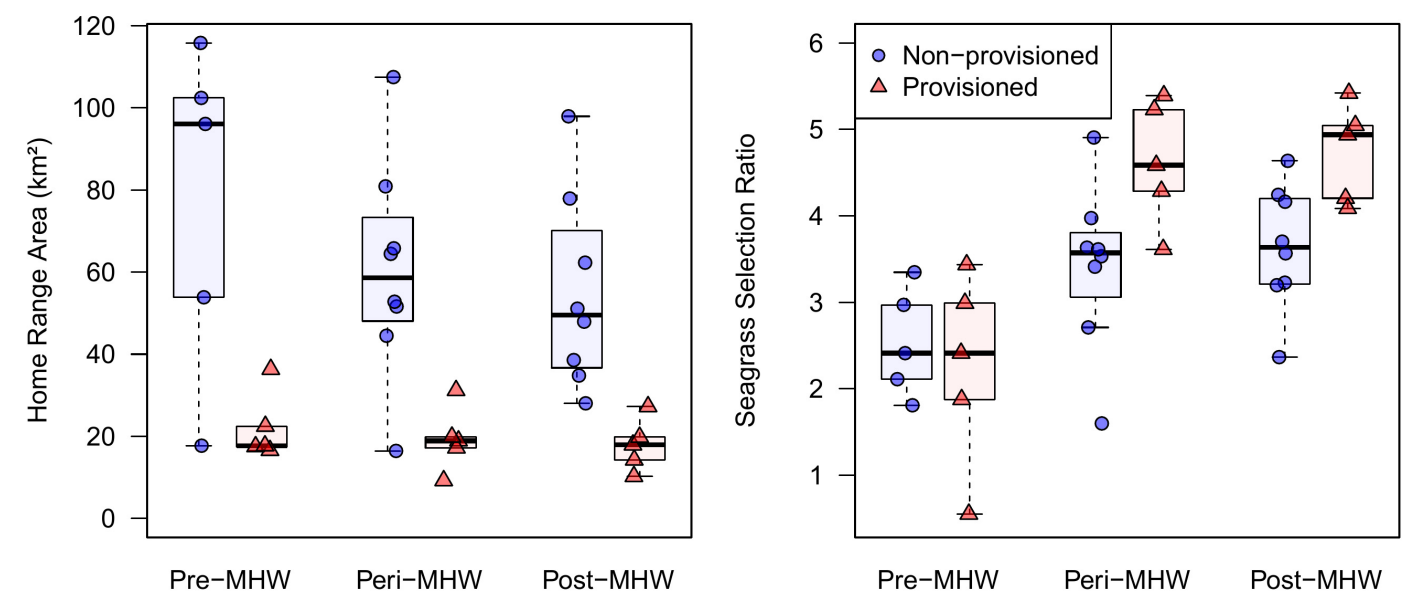

FIGURE 2 | Home range sizes and seagrass selection ratios for provisioned $(n=6)$ and non-provisioned $(n=11)$ animals in the pre (2005-2010), peri (2010-2015), and post (2015-2019) seagrass die-off periods. Home ranges and seagrass usage were estimated from averaging the results from 100 iterations of 35 randomly selected locations per animal. Home range area was derived from 95\% contours of kernel utilization distributions, and seagrass selection ratios were determined using Manly's type II design, adjusted for availability post-MHW. Provisioned animals had significantly smaller home ranges than non-provisioned ( $\beta=-55.07$, $p=0.001)$. All animals had higher seagrass selection ratios in the peri and post eras relative to pre-MHW $(\beta=1.11, p<0.024)$.

TABLE 1 | Home range size and seagrass selection ratios for provisioned and non-provisioned females in the pre-MHW (2005-2010), peri-MHW (2010-2015), and post-MHW (2015-2019) time frames.

\begin{tabular}{|c|c|c|c|c|c|c|c|c|}
\hline \multirow[b]{2}{*}{ Predictors } & \multicolumn{4}{|c|}{ Home range size } & \multicolumn{4}{|c|}{ Seagrass selection ratio } \\
\hline & Estimate & Std. error & $t$-value & $p$-value & Estimate & Std. error & $t$-value & $p$-value \\
\hline (Intercept) & 77.18 & 10.38 & 7.44 & $<0.001$ & 2.53 & 0.37 & 6.92 & $<0.001$ \\
\hline Provisioned & -55.07 & 14.67 & -3.75 & 0.001 & -0.28 & 0.52 & -0.54 & 0.596 \\
\hline Time frame [Peri] & -16.69 & 13.23 & -1.26 & 0.217 & 0.89 & 0.47 & 1.92 & 0.065 \\
\hline Time frame [post] & -22.36 & 13.23 & -1.69 & 0.101 & 1.11 & 0.47 & 2.38 & 0.024 \\
\hline Provisioned $[\mathrm{Y}]{ }^{\star}$ Time frame [peri] & 13.84 & 19.76 & 0.7 & 0.489 & 1.48 & 0.7 & 2.12 & 0.042 \\
\hline Provisioned $[\mathrm{Y}$ ] * Time frame [post] & 18.14 & 19.76 & 0.92 & 0.366 & 1.38 & 0.7 & 1.98 & 0.057 \\
\hline$R^{2}$ adjusted & 0.440 & & & & 0.499 & & & \\
\hline
\end{tabular}

Statistically significant values are indicated in bold.

TABLE 2 | Juvenile home range size is significantly correlated with maternal provisioning status, indicated in bold.

\begin{tabular}{lcccc}
\hline & \multicolumn{4}{c}{ Juvenile home range size (km²) } \\
\cline { 2 - 5 } Predictors & Estimate & Std. error & t-value & p-value \\
\hline (Intercept) & 28.33 & 22.67 & 1.25 & 0.221 \\
Mother provisioned & -28.69 & 11.15 & -2.57 & $\mathbf{0 . 0 1 5}$ \\
Sex [Male] & 13.32 & 11.43 & 1.16 & 0.253 \\
Survived [Y] & 25.23 & 18.15 & 1.39 & 0.174 \\
Weaned [pre-MHW] & 19.56 & 12.58 & 1.55 & 0.13 \\
$R^{2}$ adjusted & 0.195 & & & \\
\hline
\end{tabular}

\section{Survival \\ Calves}

Overall, calves born to provisioned mothers had higher survival than calves born to non-provisioned mothers (hazard ratio $=0.20, p=0.031$ ) (Figure 6A and Table 3). Regardless of provisioning status, there was a decline in survival post-MHW $(\mathrm{HR}=3.72,0=0.003)$, but not in the immediate aftermath of the MHW (peri-MHW, $p=0.640$ ). That is, it was several years before the ecological effects of the MHW impacted female reproduction. We did not find evidence of an interaction effect between MHW time period and provisioning status. Calving rate did not differ across time periods (Poisson GLM; peri-MHW: $p=0.875$, post-MHW: $p=0.843$ ) or by provisioning status $(p=0.737$; Supplementary material).

\section{Juveniles}

Across the whole study period, survival to age 10 did not differ between those born to provisioned and non-provisioned females ( $p=0.09$, Figure 6B and Table 3 ). This result holds when analyzing the effect of maternal provisioning on calves who were at least 3 years old, and likely weaned (i.e., likely juveniles), before the MHW (calves born between January 01, 1994 and July 01, 2007, $p=0.29$, Supplementary Table 1). As survival to age three was higher for provisioned animals in the same time period, these results suggest that the benefits of provisioning do not persist after weaning. Due to low calf survival post-MHW, and the fact that the few surviving calves born in the post-MHW period are currently under 3 years of age, we did not have sufficient sample 


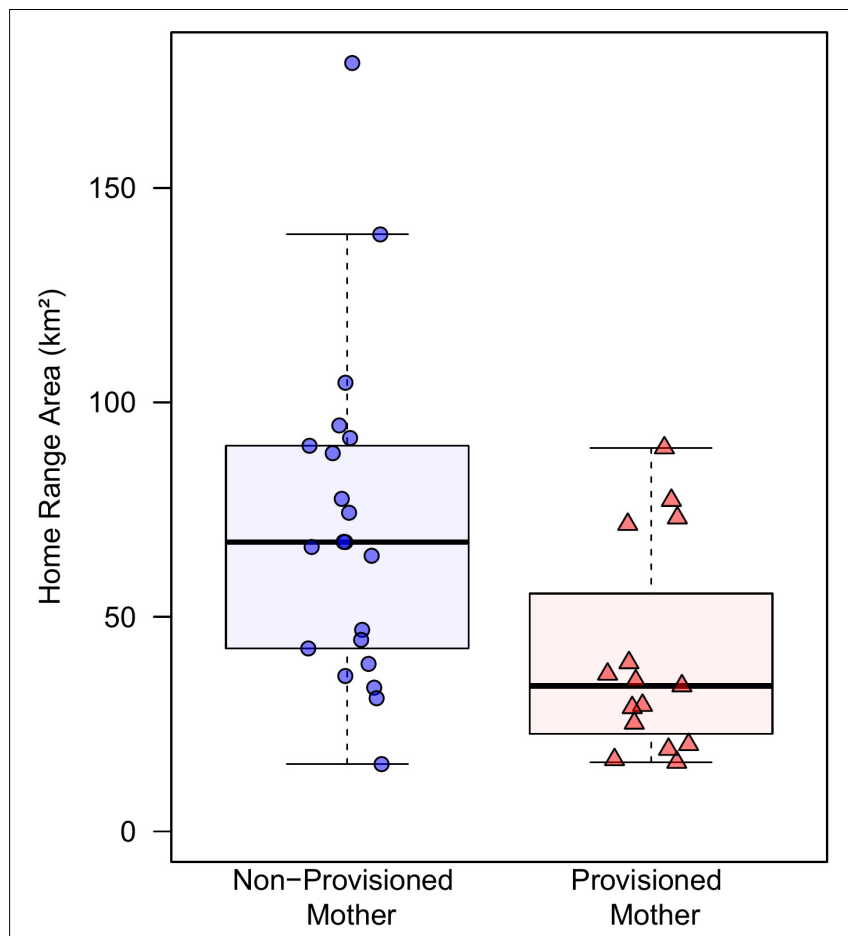

FIGURE 3 | Home range sizes for juvenile offspring (weaning to age 10) of provisioned ( $n_{\text {offspring }}=15$ ) and non-provisioned $\left(n_{\text {offspring }}=21\right)$ females who were also seagrass specialists. Offspring of provisioned mothers had significantly smaller home ranges $(\beta=-28.69, p=0.015)$. There were no significant effects of sex, survival status, or whether the offspring was weaned before or after the MHW.

size or time frame to examine the effects of MHW time period on juvenile survival.

\section{Shark Bite Rates}

We documented 89 unique shark injuries sustained by seagrass specialists and their offspring between 2002 and 2019. Mean annual probability of receiving a non-lethal wound was slightly higher among adults (provisioned $=0.247$ bites/year, nonprovisioned $=0.213 \mathrm{bites} /$ year), than among their calves and juvenile offspring (provisioned $=0.180$ bites/year, nonprovisioned $=0.141$ bites/year) likely because attacks may have been more lethal to younger dolphins. We found no significant differences in the probability of sustaining a shark injury between provisioned and non-provisioned adults (Table 4), or their offspring (Table 5), and no significant changes associated with the MHW.

\section{DISCUSSION}

To our knowledge, this is the first study to compare how provisioned and non-provisioned wildlife respond to extreme climate events and habitat devastation. Given individual variation within a population, longitudinal studies are the best way to document the social, ecological, and demographic impacts of climate events and individual resilience. As these events become more frequent, research such as that presented here can help guide management practices and mitigation. This is particularly important for marine taxa, which are more threatened than terrestrial species in this rapidly changing climate (Munday, 2004; Thomas et al., 2004; Brierley and Kingsford, 2009; Maclean and Wilson, 2011).

Bottlenose dolphins have slow life histories, high learning and innovative ability (Patterson and Mann, 2015) and like humans, might be better equipped to adapt to dramatic environmental change than less behaviorally plastic species (Pearson et al., 2014). However, Shark Bay bottlenose dolphins exhibit diverse foraging tactics that are individually-specific (Mann and Sargeant, 2003; Sargeant and Mann, 2009). Some of these involve specializations, such as beaching to catch fish (Sargeant et al., 2005) or tool use with marine sponges (Mann et al., 2008). Specialization could constrain how animals adapt to environmental change (e.g., Warren et al., 2001; Jiguet et al., 2007), but this depends on how their primary resources were impacted. Nowicki et al. (2019) found that generalist species, tiger sharks and loggerhead turtles, fared well after the 2011 MHW, but more specialized vertebrates such as dugongs, sea snakes, and green turtles, that rely heavily on seagrass habitat did not. Although Shark Bay dolphins do exhibit specialization in habitat use and foraging behavior, they feed on diverse fish species within a given habitat and, with few exceptions, use more than one habitat. That said, seagrass foragers were clearly devastated by the 2011 MHW and they responded by becoming more, not less, specialized. In fact, provisioned dolphins became even more specialized than other seagrass foragers, which likely exacerbated the impact of the MHW. Our findings are consistent with the view that specialists are more vulnerable to environmental damage and climate change (e.g., Davey et al., 2012; Lurgi et al., 2012), as they are unlikely to change strategy, but it depends on which resources are affected, not specialization per se (Bridle et al., 2014). The Shark Bay dolphin population, which has been studied for nearly four decades, provides a relatively clear picture of how individuals respond to extreme climate events and colossal habitat loss.

Our results show that most dolphins spent more time in seagrass habitats after the MHW, and this, combined with a higher prey chase rate (Miketa, 2018), suggests that dolphins found prey catches easier in the less dense seagrasses. Nowicki et al. (2019) found that although total fish abundance declined, fish aggregated more in small seagrass patches post-MHW, making them predictable targets. Even dolphins that were not seagrass specialists spent more time in seagrass habitats post-MHW (Miketa, 2018), suggesting that there were, in the immediate aftermath of the MHW, benefits to hunting in those damaged habitats, even for those presumably less-skilled at exploiting this niche. The benefit was short-lived, perhaps hampered by increased intra-specific competition, evidenced by elevated calf mortality among dolphins that specialized in seagrass habitats. Furthermore, the fact that female dolphins who specialize in seagrass habitats did not increase their home ranges suggests that dolphins focused on hunting areas that they knew well. This strategy might have also worked in the first few years after the MHW, but was not sustainable over longer periods of time. 


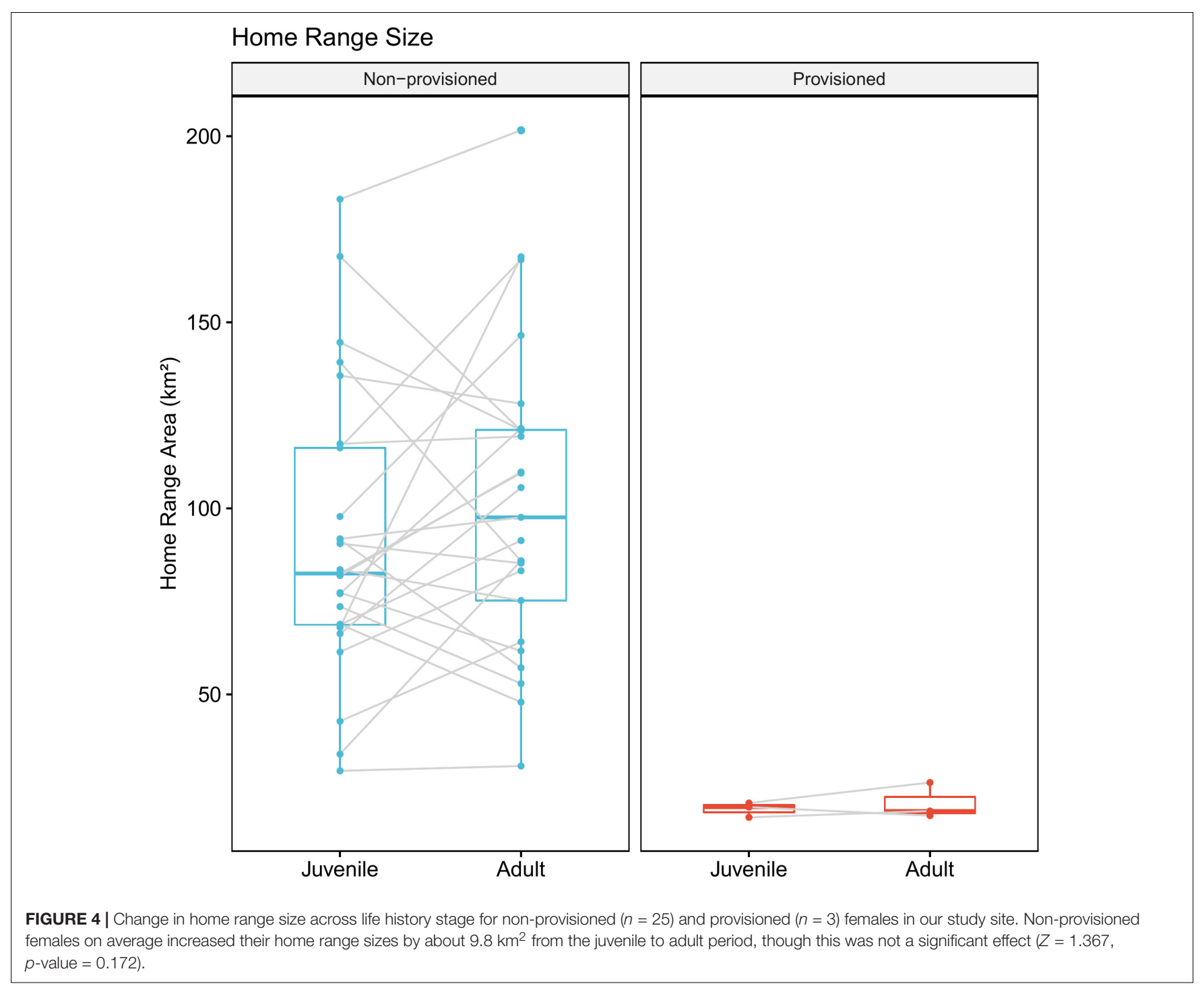

For the provisioned dolphins, the picture is arguably more complex because they had both the benefit of a reliable food source, but also an array of costs from human activity. With the boat launch area adjacent to the provisioning area, provisioned dolphins are exposed to constant boat traffic (recreational, commercial fisheries, and dolphin-watch tourism), which can have deleterious consequences (Bejder et al., 2006; New et al., 2020). In addition to direct human contact near shore, altered activity budgets, enhanced risk of injury and disease (Foroughirad and Mann, 2013; Nelson et al., 2019), and as we show here, contracted and static home ranges with age when compared to non-provisioned dolphins, likely have adverse consequences for female foraging ecology as well as social behavior. This, combined with the finding that offspring of provisioned dolphins had significantly higher calf survival, but did not have higher juvenile survival than non-provisioned, suggests that the benefits of provisioning stop at weaning.

Furthermore, provisioned dolphins limited ranges also put them at risk of limited social contact with other females. Poor social integration has fitness consequences among adult females (Frère et al., 2010) and juvenile males in this population (Stanton and Mann, 2012). Offspring of provisioned dolphins begin to show multiple behavioral differences as calves (Foroughirad and Mann, 2013) and, as shown here, socially inherit the small home ranges of their mothers. These maternal effects appear to be longlasting. Prior to the MHW, provisioned dolphins had higher offspring survival than their non-provisioned counterparts, consistent with studies of supplemental feeding for research and conservation (Murray et al., 2016). Both pre and postweaning, significant and long-lasting behavioral changes are evident (Foroughirad and Mann, 2013; this study). Furthermore, provisioning did not appear to buffer dolphins from the impact of the 2011 MHW. Collectively, these findings suggest long-term costs to provisioned dolphins and their offspring.

All seagrass specialists suffered reproductive decline postMHW, but this impact was not immediate. From 2011 to 2015, calf survival and birthrates for seagrass specialists were unchanged; this contrasts with findings by Wild et al. (2019) 

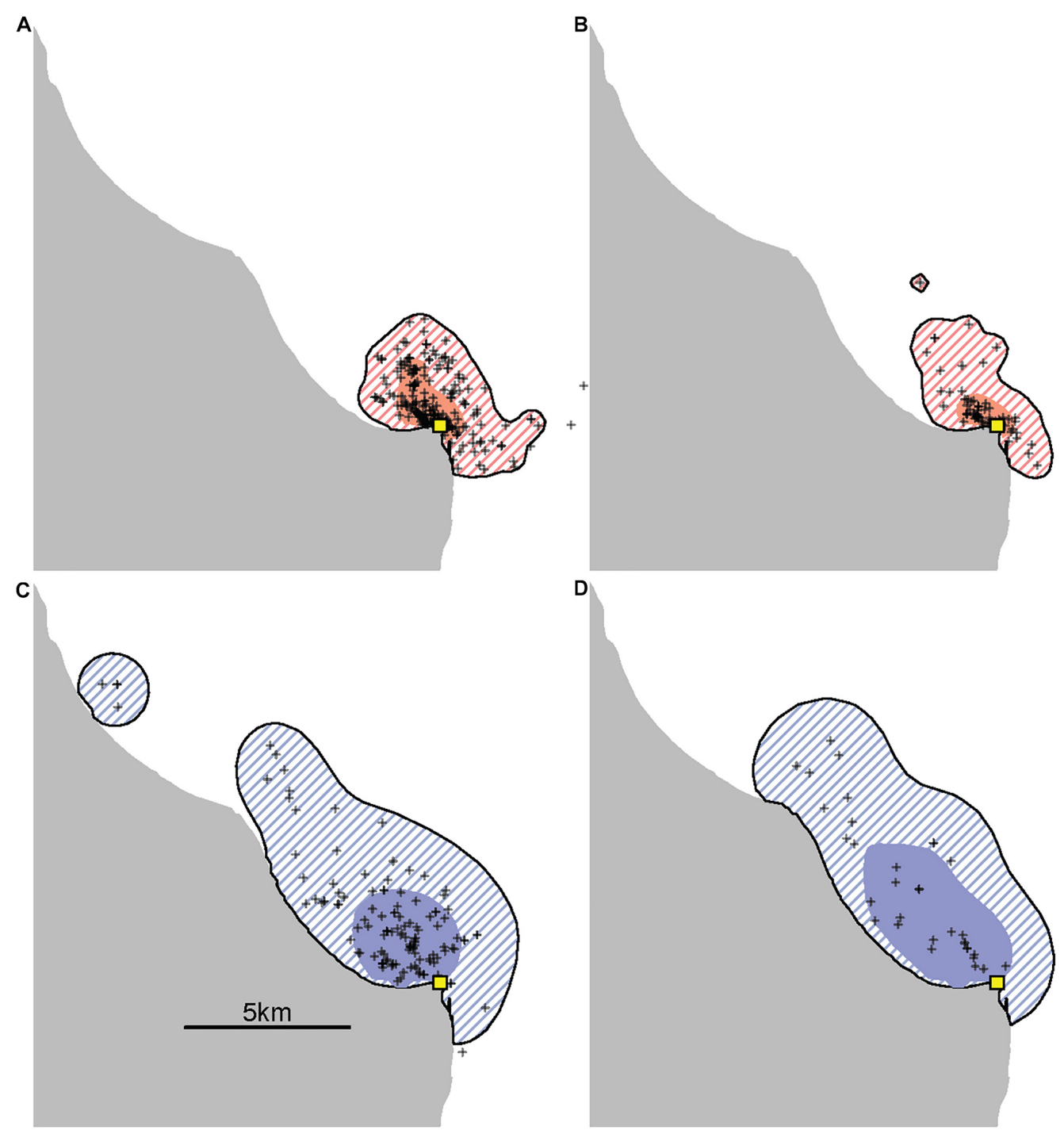

FIGURE 5 | An example of the effects of provisioning on the ranging patterns of an adult female. Kiya (top) is the offspring of a provisioned female and began accepting fish herself in 2016 when she was 18 years old, well into adulthood. This is contrasted with her paternal half-sister, Rhombus (bottom), who was born the same year and is also a seagrass specialist, but who is neither provisioned nor the offspring of a provisioned female. Using all available adult sightings excluding consortships (range 33-228 per panel) the size of Kiya's 95\% kernel contour decreased from $14.8 \mathrm{~km}^{2}$ before (A) to $11.3 \mathrm{~km}{ }^{2}$ after (B) the start of provisioning, while her $50 \%$ kernel contour decreased from $2.8 \mathrm{~km}^{2}$ to only $1.3 \mathrm{~km}^{2}$. During the same time periods, her sister Rhombus had $95 \%$ kernel contour areas of $44.8 \mathrm{~km}^{2}$ (C) and $43.8 \mathrm{~km}^{2}$ (D) and $50 \%$ kernel contour areas of 7.7 and $12.9 \mathrm{~km}^{2}$.

in the western gulf of Shark Bay, but this is likely due to the different methods and time periods. Wild et al. (2019) used data from 2007 to 2017 and documented fewer calf births post-MHW, but did not examine calf survival. We did not find a decline in the birth rate (Supplementary Material), only a decline in calf survival, post-MHW. Birth rate is difficult to interpret in bottlenose dolphins because females nurse their offspring for such variable periods (2.6-8.5 years, Karniski et al., 2018). If calves die (typically in the first year) the birth rate would increase (Mann et al., 2000). When calf survival is high, annual birth rates decline. Under stressful conditions, females might be faced with higher calf loss, but might also wean offspring later, similar to our findings on reproductive senescence (Karniski et al., 2018).
Although the discrepancy between gulfs can likely be attributed to methodological differences, it is clear that dolphins, despite their life history traits, are vulnerable, even in a relatively pristine area with stable vital rates prior to the MHW (Manlik et al., 2016). It is also clear that the impact of extreme climate events and habitat loss critically depend on the individual's ecology and specialization.

Seagrass areas adjacent to Monkey Mia were severely impacted by the MHW (Strydom et al., 2020), affecting all of the provisioned animals and many non-provisioned animals that shared this range. These areas, close to shore, are also heavily used by recreational and dolphin-watch boats, which could exacerbate the impact of habitat degradation on the dolphins. In an extensive 


\section{Not provisioned $=+=$ Provisioned}

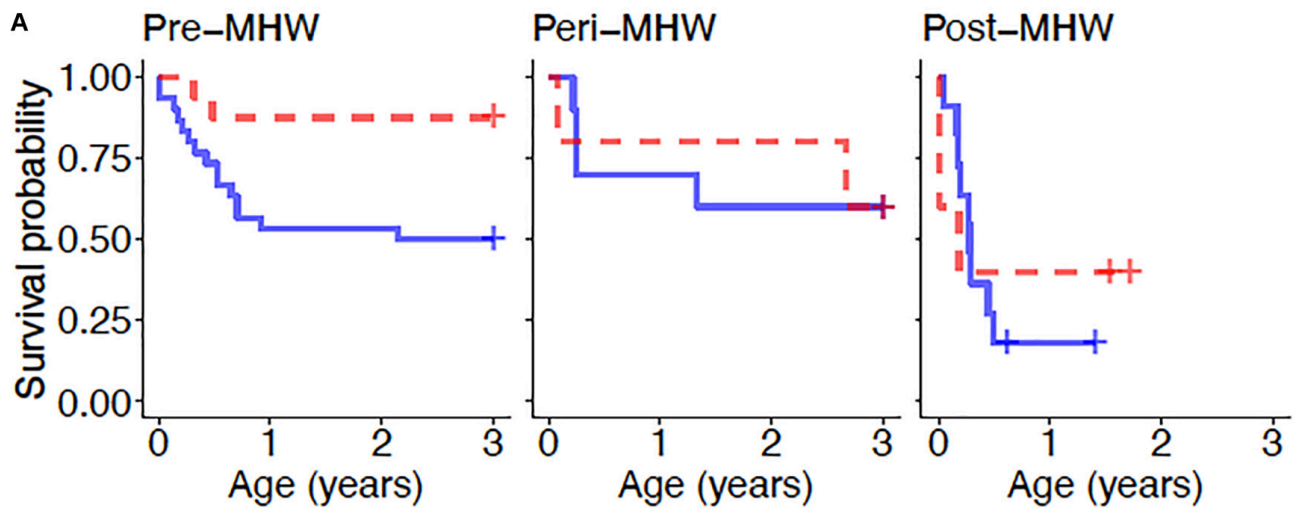

B Total study period

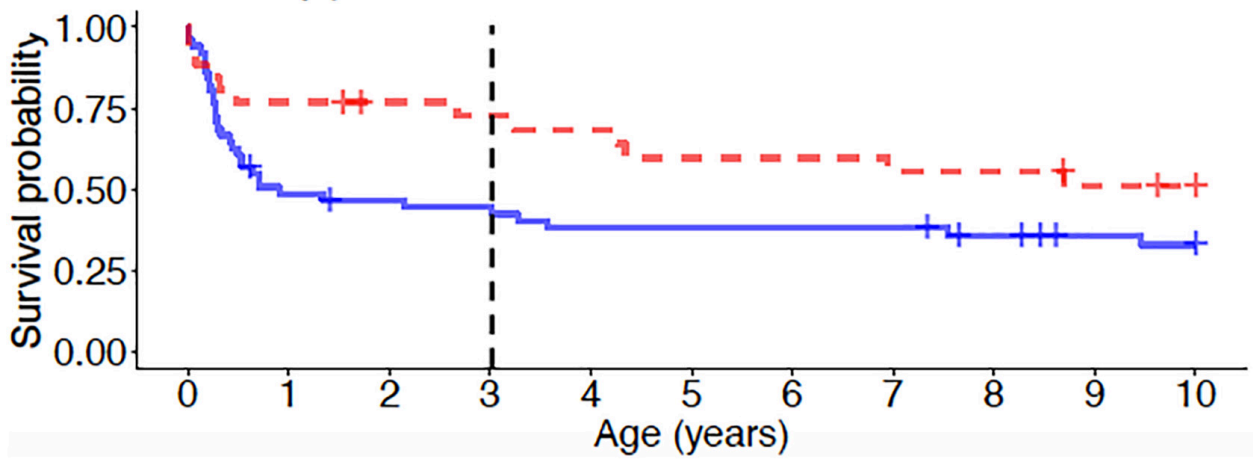

FIGURE 6 | (A) Calf survival for offspring of provisioned and non-provisioned seagrass specialists born in the pre (1994-2010), peri (2010-2015), and post (2015-2019) MHW periods and (B) juvenile survival for offspring of provisioned and non-provisioned seagrass specialists born throughout the study period (1994-2019). Across the whole study period, offspring of provisioned mothers had higher survival to age three than offspring of non-provisioned mothers $(p=0.031)$. For offspring of both provisioned and non-provisioned females, survival to age three declined in the post-MHW period $(p=0.003)$. Across the total study period, there is no significant effect of provisioning on survival to age $10(p=0.09)$, suggesting that the benefits of provisioning to offspring do not persist after weaning. The black dotted line denotes age 3 , the end of the calf period, after which the difference in survival between offspring of provisioned and non-provisioned females weakens.

review of wildlife provisioning studies worldwide, deleterious impacts were most acute when provisioning was associated with tourism, rather than for conservation efforts (Murray et al., 2016). Provisioning by tourists involves more contact with people and human activity and Monkey Mia is no exception. It is not unusual for several hundred people to be simultaneously standing in the water to get a close view of the dolphins, even though only a few people are allowed to hand feed them. Additionally, the nearshore waters are the hunting grounds for the provisioned dolphins, placing them in close proximity to people outside of the morning provisioning hours. It is clear that provisioning causes a reduced home range, consistent with a large body of research (Orams, 2002; Thomson et al., 2017; Hansen et al., 2020). With depleted seagrass habitat and a small range, even with the extra fish provisioned dolphins receive, they were severely impacted by the MHW.

Our research also shows a maternal effect on home range, in that offspring of provisioned dolphins had much smaller ranges than non-provisioned dolphins during the juvenile period, when they are independent, but still occasionally associate with their maternal kin (Tsai and Mann, 2013). Notably, the maternal effect was apparent for both males and females even though males spend very little time with their mothers post-weaning (Tsai and Mann, 2013; Krzyszczyk et al., 2017). Juveniles, typically between 4 and 10 years of age, likely continue to use foraging areas they know well. In adulthood, non-provisioned females largely maintained their juvenile home range size; female offspring of provisioned dolphins also appear to maintain their smaller inherited ranges into adulthood. Small home ranges are likely to exact ecological (and potentially social) costs in that they might further limit a dolphin's ability to respond to environmental events. This study is the first to show long-term ecological impacts of provisioning on weaned offspring, even though the offspring are not provisioned themselves.

We did not find a difference in non-lethal shark attack rate in the peri- or post-MHW period relative to before, which did not support our hypothesis that tiger sharks might have targeted bottlenose dolphins more often as their preferred prey species declined (Nowicki et al., 2019). Similar to our findings, Nowicki et al. (2019) found that dolphins were in seagrass habitats more often after the MHW, suggesting they are taking greater risks to find food because tiger sharks remained more abundant in 
these habitats (Heithaus et al., 2002). Our data on fresh shark bite rates do not suggest that dolphins were targeted more often after the MHW, but it is possible that higher calf mortality in the post-MHW period stems from elevated shark predation. Shark attacks on calves are more likely to be lethal, and we would thus not be able to document them. But when calves disappear, mothers sometimes exhibit fresh wounds, suggesting that shark attack was the cause of death of her calf. Poor physiological condition of the mother and/or calf, would increase calf vulnerability (Mann and Watson-Capps, 2005). We did not find differences in shark attack rate when comparing provisioned with non-provisioned seagrass foragers. Because we relied on

TABLE 3 | Cox proportional hazards mixed effect models for calf and juvenile survival.

\begin{tabular}{|c|c|c|c|c|}
\hline Model & Parameter & Coefficient & Hazard ratio & $p$-value \\
\hline \multirow[t]{5}{*}{ Calf survival } & $\begin{array}{l}\text { Mother } \\
\text { provisioned [Y] }\end{array}$ & -1.62 & 0.20 & 0.031 \\
\hline & $\begin{array}{l}\text { Time frame } \\
\text { [peri] }\end{array}$ & -0.26 & 0.77 & 0.640 \\
\hline & $\begin{array}{l}\text { Time frame } \\
\text { [post] }\end{array}$ & 1.31 & 3.72 & 0.003 \\
\hline & $\begin{array}{l}\text { Mother } \\
\text { provisioned [Y] } \\
\text { * Time frame } \\
\text { [peri] }\end{array}$ & 1.56 & 4.75 & 0.170 \\
\hline & $\begin{array}{l}\text { Mother } \\
\text { provisioned [Y] } \\
\text { * Time frame } \\
\text { [post] }\end{array}$ & 1.18 & 3.25 & 0.240 \\
\hline $\begin{array}{l}\text { Juvenile } \\
\text { survival }\end{array}$ & $\begin{array}{l}\text { Mother } \\
\text { provisioned [Y] }\end{array}$ & -0.57 & 0.56 & 0.09 \\
\hline
\end{tabular}

Statistically significant values are indicated in bold.

TABLE 4 | Annual probability of receiving a shark bite wound for non-provisioned and provisioned seagrass specialists before, during, and after the MHW.

\begin{tabular}{lcccc}
\hline & \multicolumn{4}{c}{ Adult shark bite rate } \\
\cline { 2 - 5 } Predictors & Odds ratio & Std. error & z-value & p-value \\
\hline (Intercept) & 0.23 & 0.29 & -5.1 & $<0.001$ \\
Time frame [peri] & 1.11 & 0.4 & 0.26 & 0.791 \\
Time frame [post] & 1.63 & 0.39 & 1.24 & 0.213 \\
Provisioned & 1.22 & 0.33 & 0.6 & 0.55 \\
\hline
\end{tabular}

TABLE 5 | Annual probability of receiving a shark wound for offspring of non-provisioned and provisioned seagrass specialists up to age 10, before, during, and after the MHW.

\begin{tabular}{lllll}
\hline & \multicolumn{3}{c}{ Calf and Juvenile shark bite rate } \\
\cline { 2 - 5 } Predictors & Odds ratio & Std. error & z-value & $\boldsymbol{p}$-value \\
\hline (Intercept) & 0.32 & 0.43 & -2.65 & 0.008 \\
Time frame [peri] & 0.89 & 0.38 & -0.32 & 0.751 \\
Time frame [post] & 0.77 & 0.52 & -0.51 & 0.61 \\
Provisioned & 1.34 & 0.35 & 0.84 & 0.403 \\
Age (years) & 0.89 & 0.07 & -1.72 & 0.085
\end{tabular}

documented attacks (fresh bite marks), we likely underestimated the rate of attack on non-provisioned females and their offspring, because they and their body parts are observed less often than provisioned females and their offspring. This would explain the slightly lower non-significant rate of shark attack among nonprovisioned dolphins.

After the MHW, 9 out of 20 adult females, all seagrass specialists, disappeared, including four of the six provisioned dolphins. Prior to the MHW, the annual rate of adult female disappearance was lower than after (5\% post-MHW vs. $2.8 \%$ pre$\mathrm{MHW}$ ). Poor condition amongst the provisioned dolphins was evident during the post-MHW period, and one non-provisioned 20 -year old female whose body we retrieved in 2019, was visibly emaciated with a thin blubber layer. Two studies (Nowicki et al., 2019; Wild et al., 2019) similarly suggest a decline in juvenileadult survival after the MHW using capture-mark-recapture and sighting rates. Neither study examined seagrass specialists per se. We expect that future analyses which can account for all foraging types and the timing of an individual's disappearance will show this impact is largely restricted to those reliant on seagrass habitats and, similar to our results on calf mortality, that the impact was delayed. Adult mortality is much more difficult to assess than calf mortality because it takes several years without sightings of an individual to assign death with confidence. Calf mortality is readily ascertained through repeated sightings of the mother without her young calf.

Extreme climate events influence vital rates depending on individual heterogeneity of phenotypes. Through longitudinal study, we show how human provisioning affects individual responses. Several other longitudinal studies have also found breeding costs for marine species in response to extreme climate events (e.g., the Southern fulmar, Jenouvrier et al., 2015; Adelie penguins, Lescroël et al., 2014; Weddell seals, Chambert et al., 2014), but can rarely show how individual specialists respond. Longitudinal studies of delphinids have found changes in social structure (spotted dolphins, Elliser and Herzing, 2011) and foraging behavior (common bottlenose dolphins, Smith et al., 2013), but not site fidelity (common bottlenose dolphins, Bassos-Hull et al., 2013) following hurricane events. Our results are similar with breeding costs specific to some behavioral phenotypes and changes in foraging behavior, but not overall site fidelity. Unlike studies of hurricanes and annual dips in arctic ice, seagrass habitats have not rebounded in Shark Bay, suggesting that the seagrass and fish communities have been permanently disrupted (Wernberg et al., 2013; Nowicki et al., 2017). Even though we documented impacts extending nearly 10 years beyond the MHW, it is unclear how seagrass foragers will adjust over time to the changed community composition. To date, our results suggest that dolphins appear to have responded by increasing their time in seagrass habitats, maintaining their home range sizes, and maintaining high site fidelity. These responses place the provisioned dolphins at higher risk, as they are further limited by the provisioning site and small home ranges, obvious signs of their dependency on fish hand-outs. Indeed our data suggest provisioned females' home range sizes, and therefore likely resource availability, may already be on the edge of what would be sustainable for a non-provisioned dolphin 
as their ranges are the smallest measured for any adult dolphin in the study. In fact, their home ranges are amongst the smallest reported for this genus (Sprogis et al., 2016; Nekolny et al., 2017).

Monkey Mia attracts over 100,000 tourists annually to see the provisioned dolphins, with visitors contributing to about onethird of the local economy (Jones, 2019). The site has also been the subject of dozens of documentary films, hundreds of scientific and popular articles, and a dozen books distributed worldwide. To enhance the sustainability of this program over the longterm, including responses to environmental shifts, management efforts that facilitate expansion of the provisioned dolphins' home range should be considered. For example, strategies that minimize the dolphins' time at the provisioning site, including delayed recruitment (of female offspring of provisioned dolphins) to as late in their life history as possible, preferably until they have successfully weaned their first calf, would likely provide the dolphins with more time to expand their home range, hone and diversify their foraging tactics, and establish their social network, all of which likely are critical for reproduction and survival. Offspring born to females prior to them being introduced to the provisioning program would also benefit from broader social and ecological experience. This would further the goal of reducing dolphin dependency on the provisioning program. With pervasive damage to the ecosystem and few signs of recovery, extreme caution is warranted with any plan to recruit more dolphins to provisioning. Given our long-term research, Monkey Mia has long served as a model for science-based management and conservation. Other provisioning sites have changed their feeding protocols as a result. Although the public clearly enjoys viewing dolphins close-up, research demonstrates that visitors to Monkey Mia overwhelmingly accept lower contact rates with dolphins if it enhances dolphin welfare (Bach and Burton, 2017). Consequently, economic interests need not conflict with sustainable management. Extreme climate events are not easily controlled given the global and pervasive nature of climate change, but with a comprehensive understanding of dolphins' foraging ecology and how they respond to catastrophic events, there are steps we can easily take to enhance the health and survival of animals that delight and inspire millions of people.

\section{DATA AVAILABILITY STATEMENT}

The raw data supporting the conclusions of this article will be made available by the authors, without undue reservation, to any qualified researcher.

\section{REFERENCES}

Ahmad, T., Khan, M., Haroon, T. H. M., Nasir, S., Hui, J., Bonilla-Aldana, D. K., et al. (2020). COVID-19: zoonotic aspects. Travel Med. Infect. Dis. 27:101607. doi: 10.1016/j.tmaid.2020.101607

Austin, P. C. (2017). A tutorial on multilevel survival analysis: methods, models and applications. Int. Stat. Rev. 85, 185-203. doi: 10.1111 /insr. 12214

\section{ETHICS STATEMENT}

The animal study was reviewed and approved by Georgetown University Animal Care and Use Committee and The Department of Parks and Wildlife (Australia).

\section{AUTHOR CONTRIBUTIONS}

JM funded and conceived of the work following the work of MLM, and previous analyses by other co-authors over the years. VF and MM analyzed the data and contributed substantially to early drafts with JM. All authors either contributed data and/or assisted in writing the manuscript. As with any longitudinal study, this work could not have been conducted without all of the authors' contributions.

\section{FUNDING}

Funding support to JM comes from NSF grants \#0847922, 0820722, 9753044, 0316800, 0918308, 0941487, 1559380, 1755229, and ONR 10230702. NSF GRFP awards to CK and MM; Georgetown University provided support to JM, MM, MLM, TE, CK, EK, EP, and MW.

\section{ACKNOWLEDGMENTS}

Many thanks to our colleagues and research assistants on the Shark Bay Dolphin Research Project. We are also grateful to the rangers and scientists at the Department of Biodiversity, Conservation and Attractions in Western Australia for logistical support. We give special thanks to Monkey Mia Resort and Royal Automobile Club of Australia for field support. Research was conducted under Georgetown University Animal Care and Use permits: IACUC-13-069, 07-041, 10-023 and 2016-1235; and Department of Parks and Wildlife Permits (Western Australia): SF-009876, SF-010347, SF-008076, SF009311, and SF007457.

\section{SUPPLEMENTARY MATERIAL}

The Supplementary Material for this article can be found online at: https://www.frontiersin.org/articles/10.3389/fmars. 2021.617550/full\#supplementary-material

Bach, L., and Burton, M. (2017). Proximity and animal welfare in the context of tourist interactions with habituated dolphins. J. Sustain. Tour. 25, 181-197. doi: 10.1080/09669582.2016. 1195835

Barber, T. M. (2016). Variety and use of objects carried by provisioned wild Australian humpback dolphins (Sousa sahulensis) in Tin Can Bay, Queensland, Australia. Int. J. Comp. Psychol. 29, $1-21$. 
Bassos-Hull, K., Perrtree, R. M., Shepard, C., Schilling, S., Barleycorn, A. A., Allen, J. B., et al. (2013). Long-term site fidelity and seasonal abundance estimates of common bottlenose dolphins (Tursiops truncatus) along the southwest coast of Florida and responses to natural perturbations. J. Cetacean Res. Manag. 13, 19-30.

Becker, D. J., Streicker, D. G., and Altizer, S. (2015). Linking anthropogenic resources to wildlife-pathogen dynamics: a review and meta-analysis. Ecol. Lett. 18, 483-495. doi: 10.1111/ele.12428

Bejder, L., Samuels, A., Whitehead, H., Gales, N., Mann, J., Connor, R., et al. (2006). Decline in relative abundance of bottlenose dolphins exposed to long-term disturbance. Conserv. Biol. 20, 1791-1798. doi: $10.1111 /$ j.1523-1739.2006.00540.x

Benhamou, S., and Cornélis, D. (2010). Incorporating movement behavior and barriers to improve kernel home range space use estimates. J. Wildlife Manag. 74, 1353-1360. doi: 10.2193/2009-441

Bichell, L. M. V., Krzyszczyk, E., Patterson, E. M., and Mann, J. (2018). The reliability of pigment pattern-based identification of wild bottlenose dolphins. Mar. Mamm. Sci. 34, 113-134. doi: 10.1111/mms.12440

Boutin, S., and Lane, J. E. (2014). Climate change and mammals: evolutionary versus plastic responses. Evol. Appl. 7, 29-41. doi: 10.1111/eva.12121

Brena, P. F., Mourier, J., Planes, S., and Clua, E. (2015). Shark and ray provisioning: functional insights into behavioral, ecological and physiological responses across multiple scales. Mar. Ecol. Prog. Ser. 538, 273-283. doi: 10.3354/ meps11492

Bridle, J. R., Buckley, J., Bodsworth, E. J., and Thomas, C. D. (2014). Evolution on the move: specialization on widespread resources associated with rapid range expansion in response to climate change. Proc. R. Soc. B Biol. Sci. 281:20131800. doi: $10.1098 /$ rspb.2013.1800

Brierley, A. S., and Kingsford, M. J. (2009). Impacts of climate change on marine organisms and ecosystems. Curr. Biol. 19, R602-R614.

Calenge, C. (2006). The package "adehabitat" for the R software: a tool for the analysis of space and habitat use by animals. Ecol. Model. 197, 516-519. doi: 10.1016/j.ecolmodel.2006.03.017

Canale, C. I., and Henry, P. Y. (2010). Adaptive phenotypic plasticity and resilience of vertebrates to increasing climatic unpredictability. Clim. Res. 43, 135-147. doi: $10.3354 / \mathrm{cr} 00897$

Caputi, N., Kangas, M. I., Chandrapavan, A., Hart, A., Feng, M., Marin, M., et al. (2019). Factors affecting the recovery of invertebrate stocks from the 2011 Western Australian extreme marine heatwave. Front. Mar. Sci. 6:484. doi: 10.3389/fmars.2019.00484

Chambert, T., Rotella, J. J., and Garrott, R. A. (2014). An evolutionary perspective on reproductive individual heterogeneity in a marine vertebrate. J. Anim. Ecol. 83, 1158-1168. doi: 10.1111/1365-2656.12211

Christiansen, F., McHugh, K. A., Bejder, L., Siegal, E. M., Lusseau, D., McCabe, E. B., et al. (2016). Food provisioning increases the risk of injury in a long-lived marine top predator. R. Soc. Open Sci. 3:160560. doi: $10.1098 /$ rsos. 160560

Cox, D. T., and Gaston, K. J. (2018). Human-nature interactions and the consequences and drivers of provisioning wildlife. Philos. Trans. R. Soc. B Biol. Sci. 373:20170092. doi: 10.1098/rstb.2017.0092

Davey, C. M., Chamberlain, D. E., Newson, S. E., Noble, D. G., and Johnston, A. (2012). Rise of the generalists: evidence for climate driven homogenization in avian communities. Glob. Ecol. Biogeogr. 21, 568-578. doi: 10.1111/j.1466-8238. 2011.00693.x

Elliser, C. R., and Herzing, D. L. (2011). Replacement dolphins? Social restructuring of a resident pod of Atlantic bottlenose dolphins, Tursiops truncatus, after two major hurricanes. Mar. Mamm. Sci. 27, 39-59. doi: 10.1111/j.1748-7692.2010. 00403.x

Environment Protection and Biodiversity Conservation Act (1999). Available at: https://www.legislation.gov.au/Details/C2020C00291 (accessed September 30, 2020).

Everard, M., Johnston, P., Santillo, D., and Staddon, C. (2020). The role of ecosystems in mitigation and management of Covid-19 and other zoonoses. Environ. Sci. Policy 111, 7-17. doi: 10.1016/j.envsci.2020.05.017
Fieberg, J., and Kochanny, C. O. (2005). Quantifying home-range overlap: the importance of the utilization distribution. J. Wildlife Manag. 69, 1346-1359. doi: 10.2193/0022-541x(2005)69[1346:qhotio]2.0.co;2

Foroughirad, V., and Mann, J. (2013). Human fish provisioning has long-term impacts on the behaviour and survival of bottlenose dolphins. Biol. Conserv. 160, 242-249. doi: 10.1016/j.biocon.2013.01.001

Fox, J., Weisberg, S., Adler, D., Bates, D., Baud-Bovy, G., Ellison, S., et al. (2012). Package 'Car.'. Vienna: R Foundation for Statistical Computing.

Frère, C. H., Krützen, M., Mann, J., Connor, R., Bejder, L., and Sherwin, W. B. (2010). Social and genetic interactions drive fitness variation in a wild population of bottlenose dolphins. Proc. Natl. Acad. Sci. U.S.A. 107, 1994919954.

Hansen, M. F., Ellegaard, S., Moeller, M. M., van Beest, F. M., Fuentes, A., Nawangsari, V. A., et al. (2020). Comparative home range size and habitat selection in provisioned and non-provisioned long-tailed macaques (Macaca fascicularis) in Baluran National Park, East Java, Indonesia. Contrib. Zool. 89, 393-411. doi: 10.1163/18759866-bja10006

Harris, R. M., Beaumont, L. J., Vance, T. R., Tozer, C. R., Remenyi, T. A., PerkinsKirkpatrick, S. E., et al. (2018). Biological responses to the press and pulse of climate trends and extreme events. Nat. Clim. Change 8:579.

Heithaus, M., Dill, L., Marshall, G., and Buhleier, B. (2002). Habitat use and foraging behavior of tiger sharks (Galeocerdo cuvier) in a seagrass ecosystem. Mar. Biol. 140, 237-248. doi: 10.1007/s00227-001-0711-7

Heithaus, M. R. (2001a). Shark attacks on bottlenose dolphins (Tursiops aduncus) in Shark Bay, Western Australia: attack rate, bite scar frequencies, and attack seasonality. Mar. Mamm. Sci. 17, 526-539. doi: 10.1111/j.1748-7692.2001. tb01002.x

Heithaus, M. R. (2001b). The biology of tiger sharks, Galeocerdo cuvier, in Shark Bay, Western Australia: sex ratio, size distribution, diet, and seasonal changes in catch rates. Environ. Biol. Fish. 61, 25-36. doi: 10.1023/a:1011021210685

Hothorn, T., Hornik, K., van de Wiel, M. A., and Zeileis, A. (2008). Implementing a class of permutation tests: the coin package. J. Stat. Softw. 28, 1-23. doi: 10.18637/jss.v028.i08

Jenouvrier, S. (2013). Impacts of climate change on avian populations. Glob. Change Biol. 19, 2036-2057. doi: 10.1111/gcb.12195

Jenouvrier, S., Péron, C., and Weimerskirch, H. (2015). Extreme climate events and individual heterogeneity shape life-history traits and population dynamics. Ecol. Monogr. 85, 605-624. doi: 10.1890/14-1834.1

Jiguet, F., Gadot, A. S., Julliard, R., Newson, S. E., and Couvet, D. (2007). Climate envelope, life history traits and the resilience of birds facing global change. Glob. Change Biol. 13, 1672-1684. doi: 10.1111/j.1365-2486.2007.01386.x

Johnson, C. N., Balmford, A., Brook, B. W., Buettel, J. C., Galetti, M., Guangchun, L., et al. (2017). Biodiversity losses and conservation responses in the Anthropocene. Science 356, 270-275. doi: 10.1126/science.aam9317

Jones, P. J. (2019). A governance analysis of Ningaloo and Shark Bay Marine Parks, Western Australia: putting the 'eco'in tourism to build resilience but threatened in long-term by climate change. Mar. Policy 5:103636. doi: 10.1016/j.marpol. 2019.103636

Karniski, C., Krzyszczyk, E., and Mann, J. (2018). Senescence impacts reproduction and maternal investment in bottlenose dolphins. Proc. R. Soc. B 285:20181123. doi: 10.1098/rspb.2018.1123

Karniski, C., Patterson, E. M., Krzyszczyk, E., Foroughirad, V., Stanton, M., and Mann, J. (2015). Determining cetacean activity budgets: a comparison of surveys and individual focal follows. Mar. Mamm. Sci. 31, 839-852. doi: $10.1111 / \mathrm{mms} .12198$

Kassambara, A., Kosinski, M., Biecek, P., and Fabian, S. (2017). Package 'Survminer.' Drawing Survival Curves Using 'Ggplot2'.(R Package Version 0.3. 1.).

Kleiber, C., Zeileis, A., and Zeileis, M. A. (2020). "Package 'AER.”' R Package Version 1.24 .

Krützen, M., Barré, L. M., Möller, L. M., Heithaus, M. R., Simms, C., and Sherwin, W. B. (2002). A biopsy system for small cetaceans: darting success and wound healing in Tursiops spp. Mar. Mamm. Sci. 18, 863-878. doi: 10.1111/j.17487692.2002.tb01078.x

Krzyszczyk, E., and Mann, J. (2012). Why become speckled? Ontogeny and function of speckling in Shark Bay bottlenose dolphins (Tursiops sp.). Mar. Mamm. Sci. 28, 295-307. doi: 10.1111/j.1748-7692.2011.00483.x 
Krzyszczyk, E., Patterson, E. M., Stanton, M. A., and Mann, J. (2017). The transition to independence: sex differences in social and behavioural development of wild bottlenose dolphins. Anim. Behav. 129, 43-59. doi: 10.1016/j.anbehav.2017.04.011

Lescroël, A., Ballard, G., Grémillet, D., Authier, M., and Ainley, D. G. (2014). Antarctic climate change: extreme events disrupt plastic phenotypic response in Adélie penguins. PLoS One 9:e85291. doi: 10.1371/journal.pone.0085291

Lurgi, M., López, B. C., and Montoya, J. M. (2012). Novel communities from climate change. Philos. Trans. R. Soc. B Biol. Sci. 367, 2913-2922.

Lusseau, D., and Mancini, F. (2018). A Global Assessment of Tourism and Recreation Conservation Threats to Prioritise Interventions. Available online at: https:// arxiv.org/abs/1808.08399v1 (accessed May 16, 2020).

Maclean, I. M., and Wilson, R. J. (2011). Recent ecological responses to climate change support predictions of high extinction risk. Proc. Natl. Acad. Sci. U.S.A. 108, 12337-12342. doi: 10.1073/pnas.1017352108

Manlik, O., McDonald, J. A., Mann, J., Raudino, H. C., Bejder, L., Krützen, M. K., et al. (2016). The relative importance of reproduction and survival for the conservation of two dolphin populations. Ecol. Evol. 6, 3496-3512. doi: 10.1002/ ece 3.2130

Manly, B. F. J., McDonald, L. L., Thomas, D. L., McDonald, T. L., and Erickson, W. P. (2002). Resource Selection by Animals: Statistical Analysis and Design for Field Studies, Second Edn. Boston, MA: Kluwer.

Mann, J., and Barnett, H. (1999). Lethal tiger shark (Galeocerdo cuvier) attack on bottlenose dolphin (Tursiops sp.) calf: defense and reactions by the mother. Mar. Mamm. Sci. 15, 568-575. doi: 10.1111/j.1748-7692.1999.tb00823.x

Mann, J., Connor, R. C., Barre, L. M., and Heithaus, M. R. (2000). Female reproductive success in bottlenose dolphins (Tursiops sp.): life history, habitat, provisioning, and group size effects. Behav. Ecol. 11, 210-219. doi: 10.1093/ beheco/11.2.210

Mann, J., and Kemps, C. (2003). "The effects of provisioning on maternal care in wild bottlenose dolphins, Shark Bay, Australia," in Marine Mammals: Fisheries, Tourism and Management Issues, eds N. Gales, M. Hindell, and R. Kirkwood (Collingwood: CSIRO Publishing), 304-320.

Mann, J., and Sargeant, B. (2003). "Like mother, like calf: the ontogeny of foraging traditions in wild Indian Ocean bottlenose dolphins (Tursiops sp.)," in The Biology of Traditions: Models and Evidence, eds D. Fragaszy and S. Perry (Cambridge, MA: Cambridge University Press), 236-266. doi: 10.1017/ cbo9780511584022.010

Mann, J., Sargeant, B. L., Watson-Capps, J., Gibson, Q., Heithaus, M. R., Connor, R. C., et al. (2008). Why do dolphins carry sponges? PLoS One 3:e3868. doi: 10.1371/journal.pone.0003868

Mann, J., Senigaglia, V., Jacoby, A., and Bejder, L. (2018). "A comparison of tourism and food-provisioning among wild bottlenose dolphins at Monkey Mia and Bunbury, Australia," in Tourism and Animal Welfare, eds N. Carr and D. Broom (Oxfordshire: CABI Publishing), 85-96. doi: $10.1079 / 9781786391858.0085$

Mann, J., and Watson-Capps, J. (2005). Surviving at Sea: ecological and behavioural predictors of calf mortality in Indian Ocean bottlenose dolphins (Tursiops sp.). Anim. Behav. 69, 899-909. doi: 10.1016/j.anbehav.2004.04.024

Maréchal, L., Semple, S., Majolo, B., and MacLarnon, A. (2016). Assessing the effects of tourist provisioning on the health of wild Barbary macaques in Morocco. PLoS One 11:e0155920. doi: 10.1371/journal.pone.0155920.g005

Merrick, M. J., and Koprowski, J. L. (2017). Should we consider individual behavior differences in applied wildlife conservation studies? Biol. Conserv. 209, 34-44. doi: 10.1016/j.biocon.2017.01.021

Miketa, M. L. (2018). Social and Behavioral Responses to Environmental Stressors in Bottlenose Dolphins in Shark Bay, Australia. Doctoral dissertation, Georgetown University, Washington, DC.

Munday, P. L. (2004). Habitat loss, resource specialization, and extinction on coral reefs. Glob. Change Biol. 10, 1642-1647. doi: 10.1111/j.1365-2486.2004.00839.x

Murray, M. H., Becker, D. J., Hall, R. J., and Hernandez, S. M. (2016). Wildlife health and supplemental feeding: a review and management recommendations. Biol. Conserv. 204, 163-174. doi: 10.1016/j.biocon.2016. 10.034
Neil, D. T., and Holmes, B. J. (2008). Survival of bottlenose dolphin (Tursiops sp.) calves at a wild dolphin provisioning program, Tangalooma, Australia. Anthrozoös 21, 57-69. doi: 10.2752/089279308x274065

Nekolny, S. R., Denny, M., Biedenbach, G., Howells, E. M., Mazzoil, M., Durden, W. N., et al. (2017). Effects of study area size on home range estimates of common bottlenose dolphins Tursiops truncatus. Curr. Zool. 63, 693-701. doi: $10.1093 / \mathrm{cz} /$ zox049

Nelson, T., Wallen, M. M., Bunce, M., Oskam, C. L., Lima, N., Clayton, L., et al. (2019). Detecting respiratory bacterial communities of wild dolphinsimplications for animal health. Mar. Ecol. Press Ser. 622, 203-217. doi: 10.3354/ meps 13055

New, L., Lusseau, D., and Harcourt, R. (2020). Dolphins and boats: when is a disturbance, disturbing? Front. Mar. Sci. 7:353. doi: 10.3389/fmars.2020.00353

Noonan, M. J., Tucker, M. A., Fleming, C. H., Akre, T. S., Alberts, S. C., Ali, A. H., et al. (2019). A comprehensive analysis of autocorrelation and bias in home range estimation. Ecol. Monogr. 89:e01344.

Nowicki, R., Heithaus, M., Thomson, J., Burkholder, D., Gastrich, K., and Wirsing, A. (2019). Indirect legacy effects of an extreme climatic event on a marine megafaunal community. Ecol. Monogr. 89:e01365.

Nowicki, R. J., Thomson, J. A., Burkholder, D. A., Fourqurean, J. W., and Heithaus, M. R. (2017). Predicting seagrass recovery times and their implications following an extreme climate event. Mar. Ecol. Prog. Ser. 567, 79-93. doi: 10.3354/meps12029

O'Brien, O., Allen, S. J., Krützen, M., and Connor, R. C. (2020). Alliancespecific habitat selection by male Indo-Pacific bottlenose dolphins in Shark Bay, Western Australia. Anim. Behav. 164, 39-49. doi: 10.1016/j.anbehav.2020.03. 014

Oliver, E. C., Donat, M. G., Burrows, M. T., Moore, P. J., Smale, D. A., Alexander, L. V., et al. (2018). Longer and more frequent marine heatwaves over the past century. Nat. Commun. 9, 1-12.

Orams, M. B. (2002). Feeding wildlife as a tourism attraction: a review of issues and impacts. Tour. Manag. 23, 281-293. doi: 10.1016/s0261-5177(01)00080-2

Orams, M. B., Hill, G. J., and Baglioni, A. J. Jr. (1996). "Pushy" behavior in a wild dolphin feeding program at Tangalooma, Australia. Mar. Mamm. Sci. 12, 107-117. doi: 10.1111/j.1748-7692.1996.tb00308.x

Patterson, E. M., and Mann, J. (2015). “Cetacean innovation," in Animal Creativity and Innovation, eds A. Kaufman and J. Kaufman (Amsterdam: Elsevier), 73-120. doi: 10.1016/b978-0-12-800648-1.00004-8

Pearson, R. G., Stanton, J. C., Shoemaker, K. T., Aiello-Lammens, M. E., Ersts, P. J., Horning, N., et al. (2014). Life history and spatial traits predict extinction risk due to climate change. Nat. Clim. Change 4, 217-221. doi: 10.1038/ nclimate 2113

R Core Team (2020). R: A Language and Environment for Statistical Computing. Vienna: R Foundation for Statistical Computing.

Samuels, A., and Bejder, L. (2004). Chronic interaction between humans and freeranging bottlenose dolphins near Panama City Beach, Florida. J. Cetacean Res. Manag. 6, 69-77.

Sargeant, B. L., and Mann, J. (2009). Developmental evidence for foraging traditions in wild bottlenose dolphins. Anim. Behav. 78, 715-721. doi: 10.1016/ j.anbehav.2009.05.037

Sargeant, B. L., Mann, J., Berggren, P., and Krützen, M. (2005). Specialization and development of beach hunting, a rare foraging behavior, by wild Indian Ocean bottlenose dolphins (Tursiops sp.). Can. J. Zool. 83, 1400-1410. doi: 10.1139/Z05- 136

Sargeant, B. L., Wirsing, A. J., Heithaus, M. R., and Mann, J. (2007). Can environmental heterogeneity explain individual foraging variation in wild bottlenose dolphins (Tursiops sp.). Behav. Ecol. Sociobiol. 61, 679-688. doi: 10.1007/s00265-006-0296-8

Senigaglia, V., Christiansen, F., Sprogis, K. R., Symons, J., and Bejder, L. (2019). Food-provisioning negatively affects calf survival and female reproductive success in bottlenose dolphins. Sci. Rep. 9:8981.

Shannon, G., McKenna, M. F., Angeloni, L. M., Crooks, K. R., Fristrup, K. M., Brown, E., et al. (2016). A synthesis of two decades of research documenting the effects of noise on wildlife. Biol. Rev. 91, 982-1005.

Smith, C. E., Hurley, B. J., Toms, C. N., Mackey, A. D., Solangi, M., and Kuczaj, S. A. II (2013). Hurricane impacts on the foraging patterns of bottlenose dolphins Tursiops truncatus in Mississippi Sound. Mar. Ecol. Prog. Ser. 487, 231-244. 
Smulders, F. O. H., O’Shea, O. R., and Christianen, M. J. A. (2021). Animalborne video reveals atypical behaviour in provisioned green turtles: a global perspective of a widespread tourist activity. Glob. Ecol. Conserv. 25:e01417.

Sprogis, K. R., Raudino, H. C., Rankin, R., MacLeod, C. D., and Bejder, L. (2016). Home range size of adult Indo-Pacific bottlenose dolphins (Tursiops aduncus) in a coastal and estuarine system is habitat and sex-specific. Mar. Mamm. Sci. 32, 287-308.

Stanton, M. A., and Mann, J. (2012). Early social networks predict survival in wild bottlenose dolphins. PLoS One 7:e47508. doi: 10.1371/journal.pone.0047508

Strandin, T., Babayan, S. A., and Forbes, K. M. (2018). Reviewing the effects of food provisioning on wildlife immunity. Philos. Trans. R. Soc. B Biol. Sci. 373:20170088.

Strydom, S., Murray, K., Wilson, S., Huntley, B., Rule, M., Heithaus, M., et al. (2020). Too hot to handle: unprecedented seagrass death driven by marine heatwave in a World Heritage Area. Glob. Change Biol. doi: 10.1111/gcb.15065 [Epub ahead of print].

Therneau, T. (2015). Mixed Effects Cox Models. Vienna: CRAN.

Therneau, T. M., and Lumley, T. (2015). Package 'Survival.' R. Top. Doc. 128:112.

Thomas, C. D., Cameron, A., Green, R. E., Bakkenes, M., Beaumont, L. J., Collingham, Y. C., et al. (2004). Extinction risk from climate change. Nature 427, 145-148.

Thomson, J. A., Araujo, G., Labaja, J., McCoy, E., Murray, R., and Ponzo, A. (2017). Feeding the world's largest fish: highly variable whale shark residency patterns at a provisioning site in the Philippines. R. Soc. Open Sci. 4:170394.

Trave, C., Brunnschweiler, J., Sheaves, M., Diedrich, A., and Barnett, A. (2017). Are we killing them with kindness? Evaluation of sustainable marine wildlife tourism. Biol. Conserv. 209, 211-222.

Tsai, Y. J. J., and Mann, J. (2013). Dispersal, philopatry, and the role of fission-fusion dynamics in bottlenose dolphins. Mar. Mamm. Sci. 29, 261-279.

Wallen, M. M., Patterson, E., Krzyszczyk, E., and Mann, J. (2016). Ecological costs to females in a system with allied sexual coercion. Anim. Behav. 115, 227-236. doi: 10.1016/j.anbehav.2016.02.018
Warren, M. S., Hill, J. K., Thomas, J. A., Asher, J., Fox, R., Huntley, B., et al. (2001). Rapid responses of British butterflies to opposing forces of climate and habitat change. Nature 414, 65-69.

Wernberg, T., Smale, D. A., Tuya, F., Thomsen, M. S., Langlois, T. J., De Bettignies, T., et al. (2013). An extreme climatic event alters marine ecosystem structure in a global biodiversity hotspot. Nat. Clim. Change 3, 78-82.

Wild, S., Krützen, M., Rankin, R. W., Hoppitt, W. J., Gerber, L., and Allen, S. J. (2019). Long-term decline in survival and reproduction of dolphins following a marine heatwave. Curr. Biol. 29, R239-R240.

World Tourism Organisation (2018). UNWTO Annual Report 2017, UNWTO. Madrid: World Tourism Organisation.

World Tourism Organisation (2020). Available online at: https://www.unwto.org/ tourism-covid-19 (accessed May 16, 2020).

Worton, B. J. (1989). Kernel methods for estimating the utilization distribution in home-range studies. Ecology 70, 164-168.1.

Worton, B. J. (1995). Using Monte Carlo simulation to evaluate kernel-based home range estimators. J. Wildlife Manag. 59, 794-800.

Würsig, B., and Jefferson, T. A. (1990). Methods of photo-identification for small cetaceans. Rep. Int. Whaling Commiss. 12, 43-52.

Yamagiwa, J. (2010). "Research history of Japanese macaques in Japan," in The Japanese Macaques, eds N. Nakagawa, M. Nakamichi, and H. Sugiura (Tokyo: Springer Science \& Business Media), 3-25.

Conflict of Interest: The authors declare that the research was conducted in the absence of any commercial or financial relationships that could be construed as a potential conflict of interest.

Copyright (c) 2021 Mann, Foroughirad, McEntee, Miketa, Evans, Karniski, Krzyszczyk, Patterson, Strohman and Wallen. This is an open-access article distributed under the terms of the Creative Commons Attribution License (CC BY). The use, distribution or reproduction in other forums is permitted, provided the original author(s) and the copyright owner(s) are credited and that the original publication in this journal is cited, in accordance with accepted academic practice. No use, distribution or reproduction is permitted which does not comply with these terms. 